\title{
Modeling of Crystalline Silicotitanate Ion Exchange Columns
}

by

D. D. Walker

Westinghouse Savannah River Company

Savannah River Site

Aiken, South Carolina 29808

This paper was prepared in connection with work done under the above contract number with the U.S.

Department of Energy. By acceptance of this paper, the publisher and/or recipient acknowledges the U.S. Government's right to retain a nonexclusive, royalty-free license in and to any copyright covering this paper, along with the right to reproduce and to authorize others to reproduce all or part of the copyrighted paper. 


\section{DISCLAIMER}

This report was prepared as an account of work sponsored by an agency of the United States Government. Neither the United States Government nor any agency thereof, nor any of their employees, makes any warranty, express or implied, or assumes any legal liability or responsibility for the accuracy, completeness, or usefulness of any information, apparatus, product, or process disclosed, or represents that its use would not infringe privately owned rights. Reference herein to any specific commercial product, process, or service by trade name, trademark, manufacturer, or otherwise does not necessarily constitute or imply its endorsement, recommendation, or favoring by the United States Government or any agency thereof. The views and opinions of authors expressed herein do not necessarily state or reflect those of the United States Government or any agency thereof.

This report has been reproduced directly from the best available copy.

Available to DOE and DOE contractors from the Office of Scientific and Technical Information, P.O. Box 62, Oak Ridge, TN 37831; prices available from (615) 576-8401.

Available to the public from the National Technical Information Service, U.S. Department of Commerce, 5285 Port Royal Road, Springfield, VA 22161. 


\section{DISCLAIMER}

Portions of this document may be illegible in electronic image products. Images are produced from the best available original document. 
WSRC-TR-98-00343, Rev. 0

Keywords: Salt processing, High level waste

Retention: Permanent

\section{MODELING OF CRYSTALLINE SILICOTITANATE ION EXCHANGE COLUMNS}

D. D. Walker

Publication Date: October 2, 1998

Westinghouse Savannah River Company

Savannah River Technology Center

Aiken, SC 29808

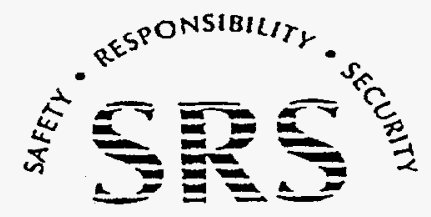

SAVANNAH RIVER SITE 


\section{Modeling of Crystalline Silicotitanate Ion Exchange Columns}

Author

$\frac{\text { Garrelet Ualber }}{\text { D. D. Walker, Waste Processing Technology }} \frac{10 / 1 / 98}{\text { Date }}$

\section{Design Check}

Wiekiam B.K

W. D. King, Waste Processing Technology

$10 / 1 / 98$

(per Manual E7, Procedure 2.40)

Date

\section{Approvals}

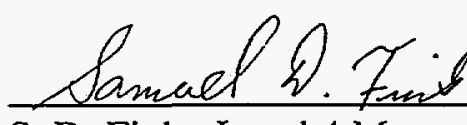

S. D. Fink, Level 4 Manager

Waste Processing Technology
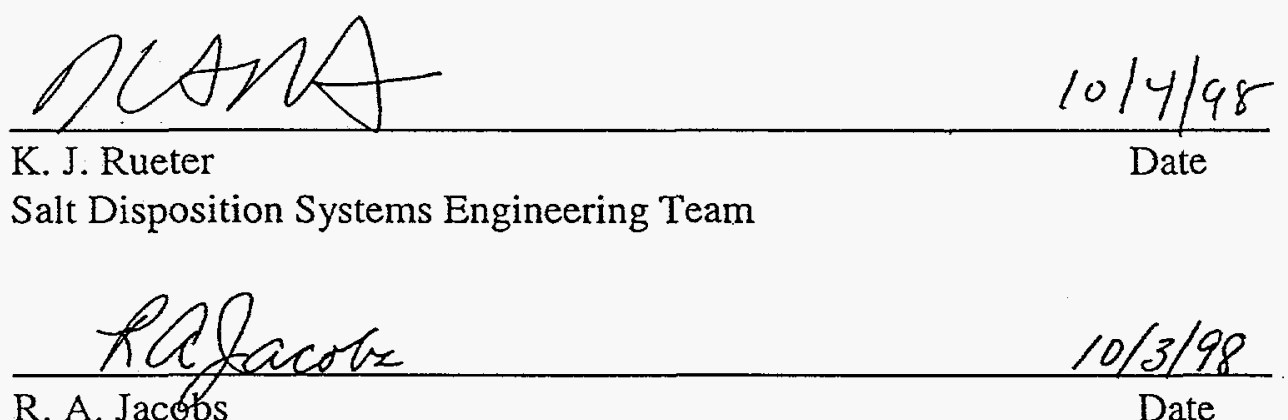

R. A. Jacobs

Date

In-Tank Precipitation Flow Sheet Team
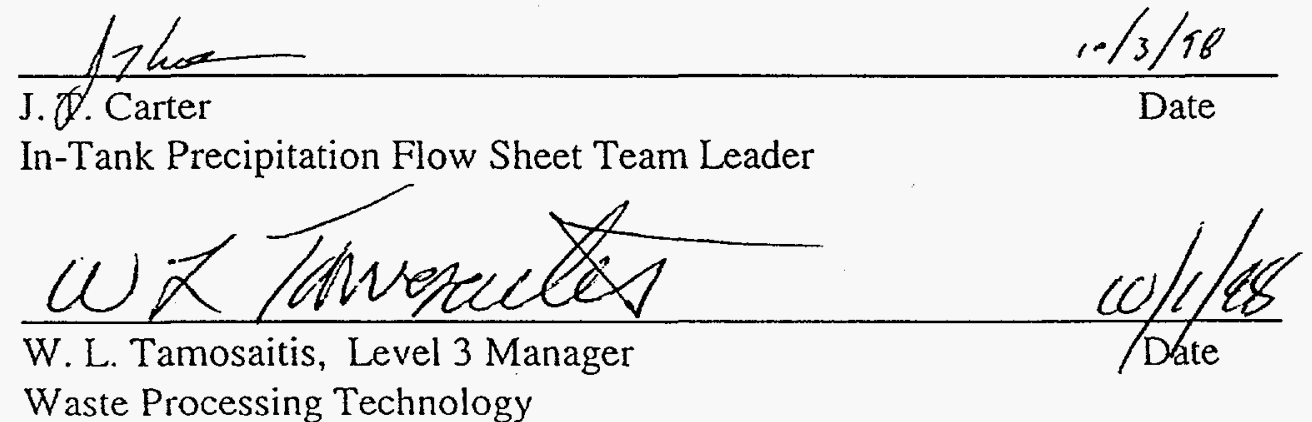

Waste Processing Technology 


\section{CONTENTS}

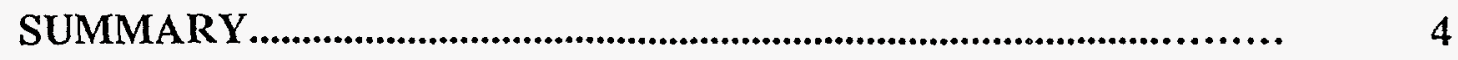

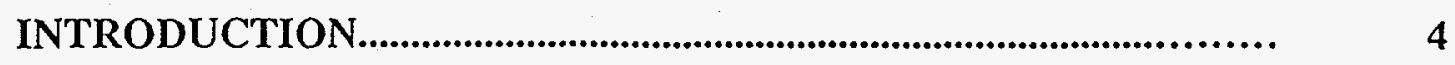

PROBLEM STATEMENT AND DESIGN PARAMETERS............. 5

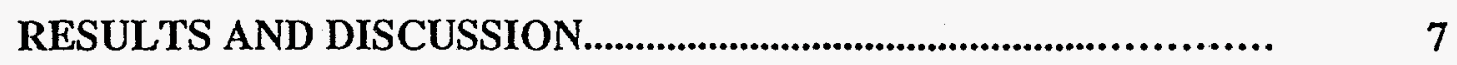

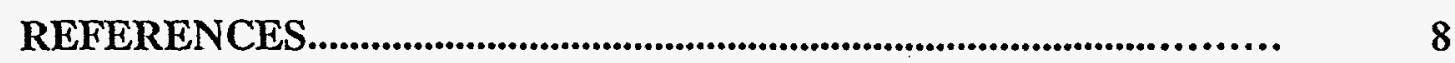

APPENDIX A: Purdue Report.............................................. 9

APPENDIX B: Texas A\&M Report.................................................... - 22 


\title{
MODELING OF CRYSTALLINE SILICOTITANATE ION EXCHANGE COLUMNS
}

\author{
By D. D. WALKER
}

\section{SUMMARY}

An ion exchange process using crystalline silicotitanate to remove cesium from Savannah River Site radioactive soluble waste was modeled by Professor R. G. Anthony, Department of Chemical Engineering, Texas A\&M University, and Professor S. W. Wang, Department of Chemical Engineering, Purdue University. The results of their calculations of column size and performance closely agree and provide a basis for preliminary design of a salt decontamination process.

- The column length required to contain the mass transfer zone (at 4-ft diameter and 25 gpm feed rate) varies between 12 and 31 feet.

-Length depends on the waste composition. High hydroxide feed requires the shortest column $(12 \mathrm{ft})$ and high nitrate waste requires the longest column (31 ft).

-At a feed rate of $15 \mathrm{gpm}$, the column lengths vary between 7 and $19 \mathrm{ft}$. -Estimates from the two modeling groups agree within $6 \%$.

- If the column length is fixed at 16 feet ( $25 \mathrm{gpm}$ feed rate), the required column diameter varies between 3.5 and 5.5 feet.

- At a feed rate of $15 \mathrm{gpm}$, the diameter varies between 2.7 and $4.3 \mathrm{ft}$.

\section{INTRODUCTION}

Non-elutable ion exchange is being considered as a potential replacement for the In-Tank Precipitation process for removing cesium from Savannah River Site (SRS) radioactive waste. ${ }^{1}$ Crystalline silicotitanate (CST) particles are the reference ion exchange medium for the process. A major factor in the construction cost of this process is the size of the ion exchange column required to meet product specifications for decontaminated waste.To validate SRS column sizing calculations, SRS subcontracted two reknowned experts in this field to perform similar calculations: Professor R. G. Anthony, Department of Chemical Engineering, Texas A\&M University, and Professor S. W. Wang, Department of Chemical Engineering, Purdue University. The appendices of this document contain reports from the two subcontractors. Definition of the design problem came through several meetings and conference calls between the participants and SRS personnel over the past few months. This document summarizes the problem definition and results from the two reports. 
This work partially fulfills a request from P. L. Rutland, Technical Task Request, "CST Ion Exchange - Salt Team Phase 3 Evaluation," \#HLE-TAR-98060, July 14, 1998.

\section{PROBLEM STATEMENT AND DESIGN PARAMETERS}

The task for the two modeling groups involved calculating the size of an ion exchange column that uses the engineered form of CST (IONSIV $\otimes \mathbb{I E - 9 1 1 ) . ~ T h e ~ p r o b l e m ~}$ statement follows.

Case 1. With column diameter fixed at $4 \mathrm{ft}$, recommend the total column length to meet the SRS effluent requirements. Parallel trains may be used to vary superficial velocity.

Case 2. With column length fixed at $16 \mathrm{ft}$, what must the column diameter be to meet SRS effluent requirements. The maximum diameter allowed is $8 \mathrm{ft}$.

Table I lists additional requirements for the calculation. The careful definition of column length is required for the problems stated above. The column length represents the minimum length required in a two column train (i.e., both columns equal in length) such that when the first column is loaded (i.e., effluent reaches $\mathrm{C} / \mathrm{Co}=0.9$ ), then the effluent from the second column meets the effluent cesium specification $(<20 \mathrm{nCi} / \mathrm{g})$. A similar statement of this requirement is that the column length is the length required to contain the mass transfer zone.

A critical input parameter in the column calculations is the isotherm for cesium absorption on CST in the presence of SRS waste solutions. Jacobs ${ }^{2}$ calculated the isotherms for the six waste compositions listed in Table I using a proprietary computer program provided by R. G. Anthony of Texas A\&M University. ${ }^{3}$ The computer program uses as a basis for equilibrium measurements of cesium absorption on the powder form of CST. Savannah River Technology Center tests ${ }^{4}$ of the engineered form of CST (IONSIV® IE-911) indicated a $30 \%$ loss of performance relative to the powder form. loss in performance may result from dilution due to the binder used in the engineered form. Because of this, the isotherms used for modeling assumed $70 \%$ of the values calculated by Jacobs. ${ }^{2}$

\section{RESULTS AND DISCUSSION}

Appendix A (Texas A\&M) and Appendix B (Purdue) contain the reports of the column calculations provided by the two modeling groups. Table II lists the results of the column calculations for nominal SRS waste compositions. The results of the calculations of column size and performance closely agree and provide a basis for preliminary design of a salt decontamination process. The column lengths calculated by the two groups agree within $6 \%$. The Texas A\&M column lengths are consistently longer. The two groups agree that the high nitrate feed composition requires the longest column and the high hydroxide feed requires the shortest column. This trend is the expected order based on 


\section{TABLE I. Design Parameters and Feed Compositions}

Effluent cesium specification

Feed flowrate

Temperature

Cs absorption isotherms

IONSIV $\circledast$ IE-911 correction factor

Loading for lead column

Bed void fraction

Particle void fraction

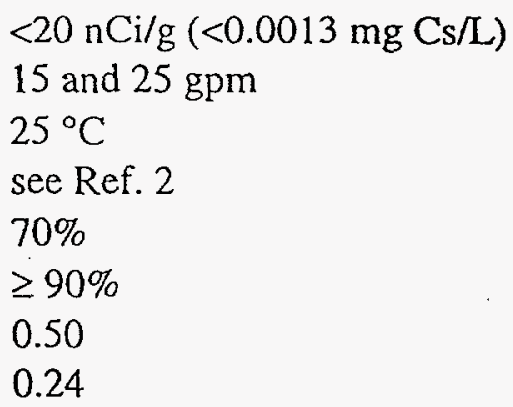

Feed compositions

Component

$\mathrm{Na}^{+}$
$\mathrm{Cs}^{+}$
$\mathrm{K}^{+}$

$\mathrm{OH}^{-}$

$\mathrm{NO}_{3}^{-}$

$\mathrm{Al}(\mathrm{OH})_{4}^{-}$

$\mathrm{CO}_{3}{ }^{2-}$

$\mathrm{SO}_{4}{ }^{2-}$

$\mathrm{Cl}^{-}$

$\mathrm{F}^{-}$

$\mathrm{PO}_{4}^{3-}$
Average

Nominal Bounding

5.6

0.000140 .00070

0.015

1.91

2.16

0.31

0.16

0.15

0.025

0.032

0.010
0.15

1.915

2.164

0.31

0.16

0.15

0.025

0.032

0.010
Concentration (molar)

High $\mathrm{OH}^{-}$

Nominal Bounding Nominal Bounding

$\begin{array}{llll}5.6 & 5.48 & 5.6 & .5 .454 \\ 0.00037 & 0.00070 & 0.00014 & 0.00070 \\ 0.030 & 0.15 & 0.0041 & 0.15 \\ 3.05 & 3.05 & 1.17 & 1.17 \\ 1.124 & 1.124 & 2.864 & 2.864 \\ 0.27 & 0.27 & 0.32 & 0.32 \\ 0.17 & 0.17 & 0.16 & 0.16 \\ 0.030 & 0.030 & 0.22 & 0.22 \\ 0.010 & 0.010 & 0.040 & 0.040 \\ 0.010 & 0.010 & 0.050 & 0.050 \\ 0.008 & 0.008 & 0.010 & 0.010\end{array}$

comparison of the cesium isotherms for the three wastes. Column length is proportional to flowrate. Decreasing the flowrate by $40 \%$ (from $25 \mathrm{gpm}$ to $15 \mathrm{gpm}$ ) shortens the columns by approximately $40 \%$.

Similar agreement occurred for Case 2 , which fixes the column length at 16 feet while varying the column diameter. Table III lists the results from the two groups. Again, differences in diameter are less than $2 \%$. 
WSRC-TR-98-00343 Rev.0

Page 7 of 69

TABLE II. Comparison of Calculated Column Lengths for Nominal SRS Waste Compositions

Feed Type $\frac{\text { Flowrate }}{\text { (gpm) }}$

High $\mathrm{OH}^{-}$

15

25

Average

15

25

High $\mathrm{NO}_{3}^{-} \quad 15$

25
Column Length $(\mathrm{ft})$ *

Texas A\&M

7.41

12.3

16.3

27.2

18.6

31.0
Purdue

7.3

12.2

15.6

25.7

18.3

30.5

*Column diameter equals $4 \mathrm{ft}$.

TABLE III. Comparison of Calculated Diameters for Nominal SRS Waste Compositions

Feed Type $\frac{\text { Flowrate }}{\text { (gpm) }}$

High $\mathrm{OH}^{-} \quad 15$

25

Average

15

25

High $\mathrm{NO}_{3}^{-} \quad 15$

25
Column Diameter (ft)*

$\underline{\text { Texas A\&M }}$

2.73

3.52

4.05

5.22

4.32

5.57 $\underline{\text { Purdue }}$

2.7

3.5

4.0

5.2

4.3

5.5

*Column length equals $16 \mathrm{ft}$. 


\section{REFERENCES}

1. P. L. Rutland et al., "Bases, Assumptions, and Results of the Flowsheet Calculations for the Initial Eighteen Salt Disposition Alternatives", WSRC-RP-98-00166, 25 June 1998.

2. R. A. Jacobs, "Powdered Crystalline Silicotitanate (CST) Isotherms for SRS Wastes (U)," WSRC-RP-98-01051, Rev.0, September 11, 1998.

3. R. G. Anthony and Z. Zheng, CST Ion Exchange Version 5 (CSTIXES5), Department of Chemical Engineering, Texas A\&M University, College Station, TX.

4. D. J. McCabe, "Examination of Crystalline Silicotitanate Applicability in Removal of Cesium from SRS High Level Waste (U)," WSRC-TR-97-0016, April 25, 1997. 
APPENDIX A

Purdue Report

\title{
Design of a Carousel Process for Removing Cesium from SRS Waste Using Crystalline Silicotitanate Ion Exchanger
}

\author{
Benjamin J. Hritzko and N.-H. Linda Wang \\ School of Chemical Engineering \\ Purdue University \\ West Lafayette, IN 47907-1283
}

September 30, 1998

\begin{abstract}
Preliminary designs of a three-column carousel process have been developed for removing radioactive ${ }^{137} \mathrm{Cs}^{+}$from Savannah River Site's nuclear wastes, based on crystalline silicotitanate (CST) ion exchanger. A multicomponent ion exchange model [16] from Texas A\&M University, which is based on batch data obtained from CST powder, is used to generate cesium loading data at different cesium concentrations. These loading data are fit to an effective single-component cesium isotherm, using the Langmuir equation. A dilution factor is used to account for the inert binder used to make pellets from the crystalline silicotitanate powder. Mass transfer parameters are estimated by analyzing existing column data for Melton Valley Storage Tank waste, and a correction is made to the intraparticle diffusivity by means of the Stokes-Einstein equation. Numerical simulations are performed to determine the length of the mass transfer zone for given feed compositions, $\mathrm{Cs}^{+}$concentrations, and linear velocities. The length of the mass transfer zone after the concentration wave reaches constant pattern is chosen to be the length of a single segment in the carousel process. Analysis of the dimensionless groups in the differential mass balance equations reveals that the normalized mass transfer zone length is linearly proportional to the particle Peclet number. The proportionality constant is a function of the waste composition and the $\mathrm{Cs}^{+}$concentration in the waste. This dimensionless group analysis allows one to easily adjust designs for variations in particle size, linear velocity, and intraparticle diffusivity.
\end{abstract}

\section{Introduction}

Over 100 million gallons of radioactive waste, generated by nuclear reactors and weapon production plants, is now in underground storage tanks (USTs) at Department of Energy (DOE) sites in Hanford, Savannah River, Oak Ridge, Idaho, and Fernald [12]. The cast for treating this waste using current technologies is estimated at 100 billion dollars [12]. After 
WSRC-TR-98-00343 Rev.0

Page 10 of 69

APPENDIX A (continued)

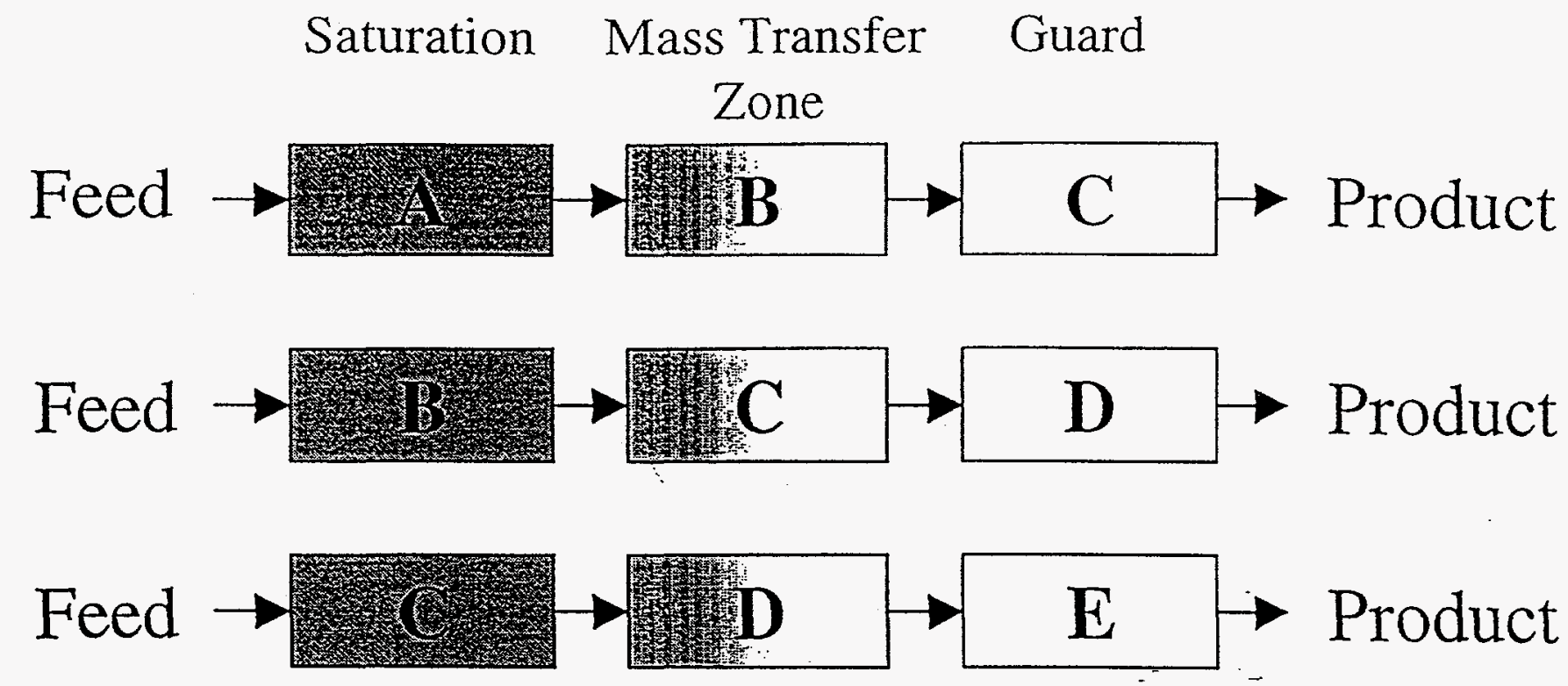

Figure 1: Proposed carousel process. Column 1. is the saturation zone. Column 2 contains the mass transfer zone. Column 3 is a guard zone.

the initial treatment, the waste in its final form is enclosed in borosilicate glass for permanent storage.

Several different approaches are currently under investigation for treating the supernatant before it is placed in long-term storage [12]. The present study is focused on CST ion exchange for treatment of Savannah River Site (SRS) wastes. CST has a high affinity for the major radioactive contaminant, ${ }^{137} \mathrm{Cs}^{+}$. Since the affinity is high, a large amount of ${ }^{137} \mathrm{Cs}^{+}$ can be confined within a small volume of saturated CST particles. Since the cost of making glass canisters is expected to be quite high. it is important to utilize the CST exchanger as much as possible. A continuous carousel process with three packed columns in series (Figure 1) is proposed. The carousel design allows the cesium level in the decontaminated waste to be below the required levels (less than $1.3 \times 10^{-3} \mathrm{mg} / \mathrm{L} \mathrm{Cs}^{+}$) and almost full utilization of the adsorbent [6].

CST ion exchanger was developed at Texas A\&M University (TAMU) in a powder form $[1,2]$ and was engineered into a pellet form by UOP. The pellet form is the CST powder mixed with an inert binder. This binder makes CST feasible for column applications, but it gives the pellets a lower effective capacity per unit weight than the powder [10,11]. Zheng et al. [16] at TAMU developed a detailed multicomponent ion exchange model that describes the uptake of $\mathrm{Cs}^{+}$on CST powder in the presence of competing ions. They validated the model via batch experiments conducted in ORNL, NCAW and other waste simtitants in 


\section{APPENDIX A (continued)}

which $\mathrm{Cs}^{+}$adsorption on CST powder was measured [16].

In this work, the TAMU model of equilibrium uptake of $\mathrm{Cs}^{+}$on CST powder has been fit to a single-component Langmuir isotherm for six different SRS waste compositions. In order to account for the inert binder, the Langmuir coefficients $a$ have been multiplied by a dilution factor of 0.7 . The isotherms and the dilution factor are to be confirmed by batch test and column test data for the SRS wastes in the near future. This approach yields effective $\mathrm{Cs}^{+}$isotherms which are needed in a dynamic column model for the carousel design.

Mass transfer parameters are estimated by analyzing Cesium Removal Demonstration (CsRD) column experiments from Oak Ridge National Laboratory (ORNL) and CsRD support column experiments. These experiments were performed on CST pellets from the same lot and with the same feed (Melton Valley Storage Tank W29, or MVST-W29) over a wide range of linear superficial velocities $(0.3$ to $10.8 \mathrm{~cm} / \mathrm{min})$. Porous column model simulations are compared to the ORNL column data and the effective intraparticle diffusivity $\left(D_{p}\right)$ is determined for MVST-W29 waste. The Stokes-Einstein equation is proposed to estimate the value of $D_{p}$ for the different SRS wastes, based on the $D_{p}$ and viscosity for MVST-W29.

The model and mass transfer parameters are used to perform-simulations on designs for treating large-scale SRS waste. The length of the mass transfer zone determines the column length requirement for the segments in a carousel process. The mass transfer zone is defined as the length of column required to contain the $\mathrm{Cs}^{+}$concentration wave from 90 percent of the feed concentration to $1.3 \times 10^{-3} \mathrm{mg} / \mathrm{L}$. An analysis of the dimensionless groups in the model has shown that the mass transfer zone length (normalized by the particle radius) depends only on the particle Peclet number. The proportionality constant in this relationship is a function of the waste composition and the $\mathrm{Cs}^{+}$concentration. Using this proportionality, one can easily determine the carousel column size at a given linear velocity, particle size, and intraparticle diffusivity.

\section{Simulation Models, Parameters, and Assumptions}

The mathematical model utilized in the simulations is a porous model which takes into account competitive adsorption, bulk convection, axial dispersion, film mass transfer, and pore diffusion. Surface diffusion effects are lumped into an apparent pore diffusion coefficient in this preliminary analysis. The numerical solutions of the governing equations and boundary conditions are performed by the VERSE simulation package $[4,14]$. This model has been validated in many previous studies $[6,7,9]$. The pore diffusion model assumes uniform spherical adsorbent particles, plug flow with constant linear velocity, local equilibrium within the adsorbent, and constant diffusivities.

\subsection{Pore Diffusion Model}

In the pore diffusion model, the material balance in the mobile phase is given by

$$
\begin{gathered}
\frac{\partial C}{\partial t}=E_{b} \frac{\partial^{2} C}{\partial z^{2}}-u_{0} \frac{\partial C}{\partial z}-\frac{3 k_{f}\left(1-\varepsilon_{b}\right)}{R_{p} \varepsilon_{b}}\left(C-C_{p, r=R_{p}}\right) \\
z=0, \quad E_{b} \frac{\partial C}{\partial z}=u_{0}\left(C(t, 0)-C_{0}\right)
\end{gathered}
$$




\section{APPENDIX A (continued)}

Table 1: Dimensionless parameters in the pore diffusion model (Eqs. 3 and 4).

\begin{tabular}{cccc}
\hline Parameter & Definition & Description & Value ${ }^{\dagger}$ \\
\hline$x$ & $z / L_{c}$ & dimensionless axial distance & $0-1$ \\
$\theta$ & $t u_{0} / L_{c}$ & dimensionless time & $0-1$ \\
$\xi$ & $r / R_{p}$ & dimensionless radial distance & $0-1$ \\
$\phi_{b}$ & $\left(1-\varepsilon_{b}\right) / \varepsilon_{b}$ & particle/bulk phase ratio & 1.0 \\
$\phi_{p}$ & $\left(1-\varepsilon_{p}\right) / \varepsilon_{p}$ & solid/pore phase ratio & 3.2 \\
$L_{c}^{*}$ & $L_{c} / R_{p}$ & dimensionless column length & $7.6 \times 10^{4}$ \\
$k_{f}^{*}$ & $k_{f} / u_{0}$ & film mass transfer/convection & $2.5 \times 10^{-2}$ \\
$\mathrm{Pe}_{b}$ & $u_{0} L_{c} / E_{b}$ & convection/axial dispersion & $4.4 \times 10^{4}$ \\
$\mathrm{Pe}_{p}$ & $u_{0} R_{p} / D_{p}$ & convection/intraparticle diffusion & $3.6 \times 10^{3}$ \\
\hline
\end{tabular}

$\dagger$ I.D. $=4 \mathrm{ft} . L_{c}=16 \mathrm{ft} . u_{s}=4.9 \mathrm{~cm} / \mathrm{min} . R_{p}=187.5 \mu \mathrm{m} . D_{p}=5.0 \times 10^{-5} \mathrm{~cm}^{2} / \mathrm{min}$.

$$
\begin{array}{cc}
z=L_{c}, & \frac{\partial C}{\partial z}=0 \\
t=0, & C=C(0, z)
\end{array}
$$

where $C$ is the mobile phase concentration $(\mathrm{mg} / \mathrm{mL}), t$ is time ( $\mathrm{min}), E_{b}$ is the axial dispersion coefficient $\left(\mathrm{cm}^{2} / \mathrm{min}\right), z$ is the axial distance along the column $(\mathrm{cm}), u_{0}$ is the mobile phase velocity $(\mathrm{cm} / \mathrm{min}), k_{f}$ is the film mass transfer coefficient $(\mathrm{cm} / \mathrm{min}), R_{p}$ is the particle radius $(\mathrm{cm})$, and $C_{p, r=R_{p}}$ is the particle phase solute concentration at the surface $(\mathrm{mg} / \mathrm{mL})$. In the pore phase, the material balance equation is

$$
\begin{array}{cc}
\left(\varepsilon_{p}+\left(1-\varepsilon_{p}\right) \frac{\partial q}{\partial C_{p}}\right) & \frac{\partial C_{p}}{\partial t}=\varepsilon_{p} \frac{D_{p}}{r^{2}} \frac{\partial}{\partial r}\left(r^{2} \frac{\partial C_{p}}{\partial r}\right) \\
r=0, & \frac{\partial C_{p}}{\partial r}=0 \\
r=R_{p}, & \varepsilon_{p} D_{p} \frac{\partial C_{p}}{\partial r}=k_{f} R_{p}\left(C-C_{p, r=R_{p}}\right) \\
t=0, & C_{p}=C_{p}(0, r)
\end{array}
$$

where $C_{p}$ is the pore-phase concentration $(\mathrm{mg} / \mathrm{mL}), q$ is the solid-phase concentration $(\mathrm{mg} / \mathrm{mL}$ S.V.), $r$ is the distance in the radial direction $(\mathrm{cm})$, and $D_{p}$ is the intraparticle diffusivity $\left(\mathrm{cm}^{2} / \mathrm{min}\right)$.

Eqs. 1 and 2 and their boundary conditions can be rewritten as follows in terms of the dimensionless quantities listed in Table 1.

$$
\begin{aligned}
& \frac{\partial C}{\partial \theta}=\frac{1}{\mathrm{Pe}_{b}} \frac{\partial^{2} C}{\partial x^{2}}-\frac{\partial C}{\partial x}-3 L_{c}^{*} \phi_{b} k_{f}^{*}\left(C-C_{p, \xi=1}\right) \\
& x=0, \frac{\partial C}{\partial x}=\mathrm{Pe}_{b}\left(C-C_{0}(\theta)\right) \\
& x=1, \quad \frac{\partial C}{\partial x}=0 \\
& \theta=0, \quad C=C(0, x)
\end{aligned}
$$


APPENDIX A (continued)

$$
\begin{gathered}
\left(1+\phi_{p} \frac{\partial q}{\partial C_{p}}\right) \frac{\partial C_{p}}{\partial \theta}=L_{c}^{*} \frac{1}{\mathrm{Pe}_{p}} \frac{1}{\xi^{2}} \frac{\partial}{\partial \xi}\left(\xi^{2} \frac{\partial C_{p}}{\partial \xi}\right) \\
\xi=0, \quad \frac{\partial C_{p}}{\partial \xi}=0 \\
\xi=1, \quad \frac{\partial C_{p}}{\partial \xi}=\frac{1}{1+\phi_{p}} \operatorname{Pe}_{p} k_{f}^{*}\left(C-C_{p}\right) \\
\theta=0, \quad C_{p}=C_{p}(0, \xi)
\end{gathered}
$$

\subsection{Effective $\mathrm{Cs}^{+}$Isotherm Approach for Complex Wastes}

Figure 2 shows effective $\mathrm{Cs}^{+} / \mathrm{CST}$ isotherms based on TAMU model predictions for the various SRS wastes and W29. Figure 3 shows the TAMU model predictions for the SRS standard simulant and the batch test data for CST powder [10] and CST pellets [11]. The experimental data are in reasonable agreement with the model predictions. The waste is a complex multicomponent mixture and the TAMU model [16] is able to predict the adsorption capacity of $\mathrm{Cs}^{+}$at various feed $\mathrm{Cs}^{+}$concentrations for the SRS staidard simulant. In our simulations, we chose a simple Langmuir isotherm to describe the equilibrium uptake of $\mathrm{Cs}^{+}$on CST. We fit the TAMU model isotherms to individual Langmuir isotherms, and then found it necessary to multiply the Langmuir coefficients $a$ by a dilution factor to take into account the inert binder that is used in engineered-form CST exchangers. This factor has been justified in two separate instances. Figure 3 shows experimental batch data for powdered CST (DG-112) and batch data for the engineered form (38-B), both in SRS standard simulant. The maximum capacity (at high concentration) of the engineered form is 56 percent of that of the powdered form. At low concentrations, the dilution factor is between 0.7 and 1.0. The solid line shows that the TAMU model can predict $\mathrm{Cs}^{+}$uptake on the powdered CST reasonably well. The uptake of $\mathrm{Cs}^{+}$on the engineered form is in reasonable agreement with the TAMU model prediction multiplied by dilution factors of 0.56 and 0.7 (dashed lines in Figure 3). In a second case, shown in Figure 4, the TAMU model for $\mathrm{Cs}^{+}$ uptake on powdered CST in the MVST-29 waste is denoted by a solid line. The two dotted lines show the best-fit Langmuir isotherms to column data performed on engineered CST with the MVST-W29 waste (dilution factors of 0.56 and 0.66 ). All of the column data were well-predicted by isotherms within this range. The maximum capacities determined from these two isotherms (on engineered CST) are 56 percent and 66 percent of that of the powdered form CST. A dilution factor of 0.7 is assumed in the simulations in this study. Table 2 lists the Langmuir isotherm parameters for various SRS wastes.

\subsection{Mass Transfer Parameters}

The Brownian diffusivity for W29 is taken from the work of Ernest et al. [6]. A Brownian diffusivity for the SRS wastes is assumed to be 50 percent of that for W29. The film mass transfer coefficient, $k_{f}$, is calculated from the correlation by Wilson and Geankoplis [15] and the axial dispersion coefficient, $E_{b}$, is calculated from the correlation by Chung and Wen [5]. These parameters were used to analyze ORNL CST small-scale (10 $\mathrm{mL})$ column data [8] and large-scale $(38 \mathrm{~L})$ column data [13]. Simulation results were compared to the 
APPENDIX A (continued)

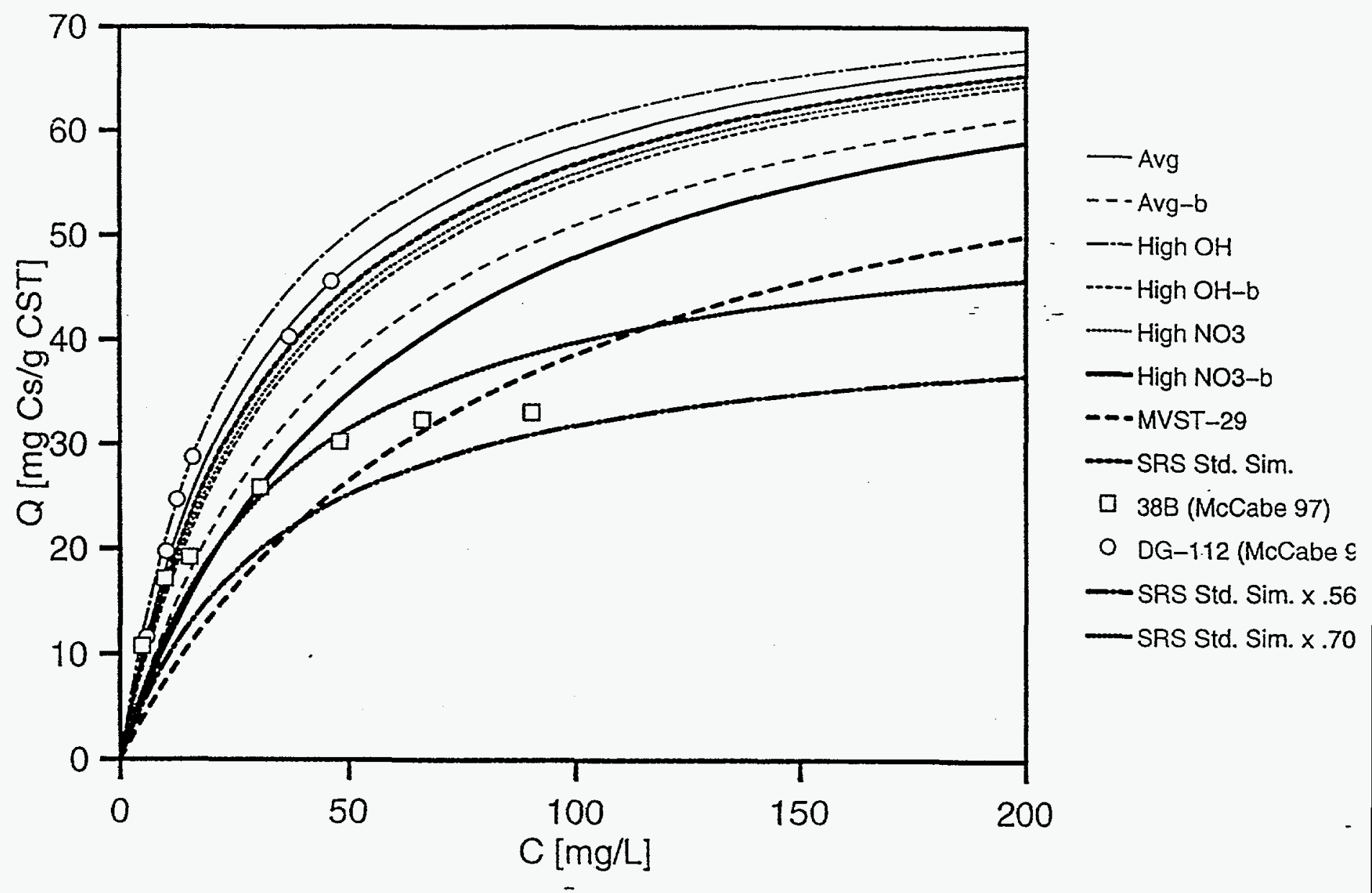

Figure 2: $\mathrm{Cs}^{+} / \mathrm{CST}$ isotherms showing model predictions of bounding cases: average SRS, high hydroxide, and high nitrate. Experimental data are shown in symbols. 


\section{APPENDIX A (continued)}

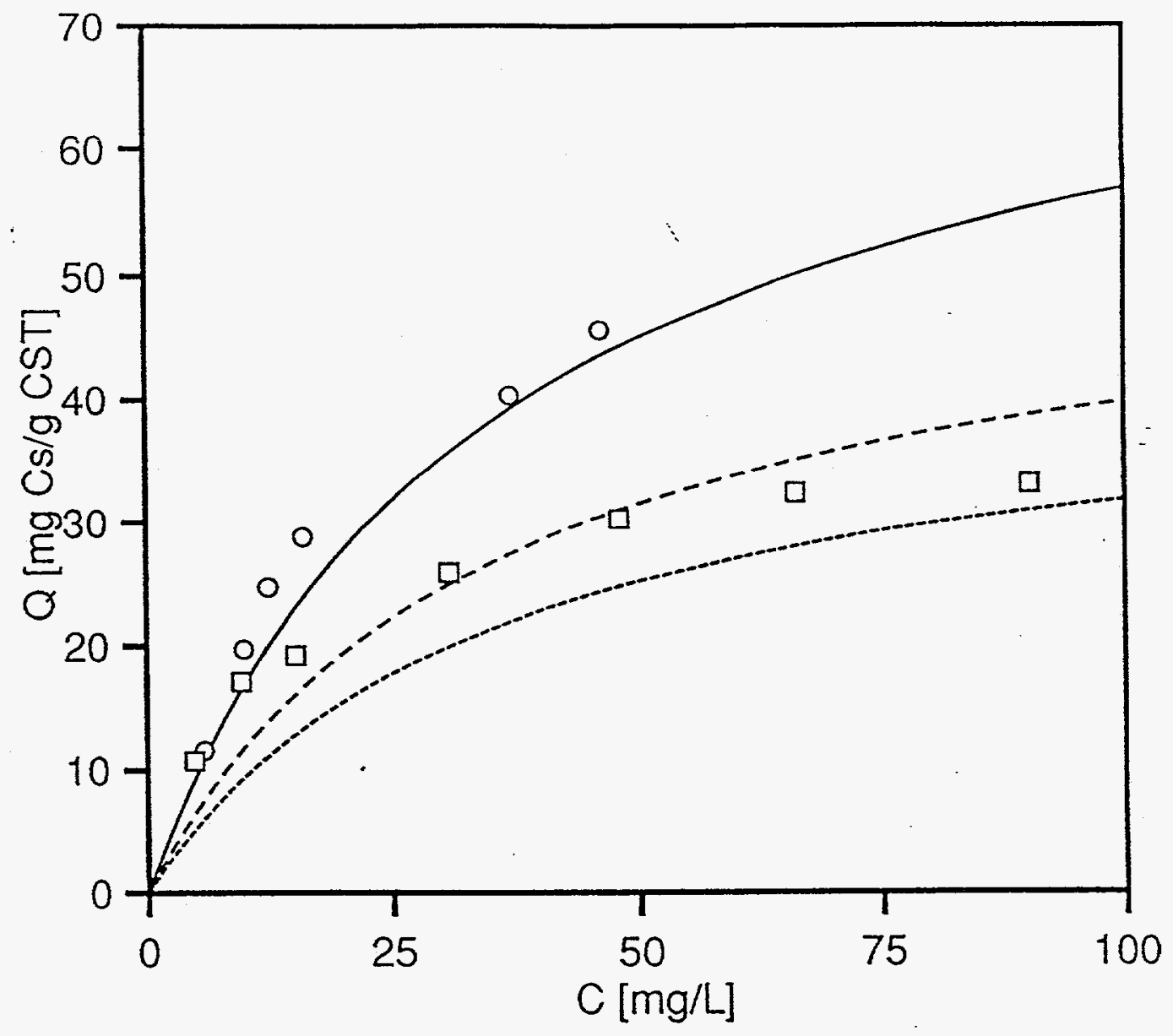

$38 \mathrm{~B}$ pellet (McCabe)

- DG-112 powder (McCabE

- SRS Std. Sim.

---SRS Std. Sim. $x .7$

-.---SRS Std. Sim. $\times .56$

Figure 3: $\mathrm{Cs}^{+} / \mathrm{CST}$ isotherms in SRS high level waste. The solid line denotes $\mathrm{Cs}^{+}$uptake on powdered CST; circles denote experimental batch $\mathrm{Cs}^{+}$uptake on powdered CST. Triangles denote batch equilibrium data performed on an engineered CST (38-B). The dashed lines are obtained by multiplying the Langmuir $a$ of the model prediction by 0.56 and 0.7 . 


\section{APPENDIX A (continued)}

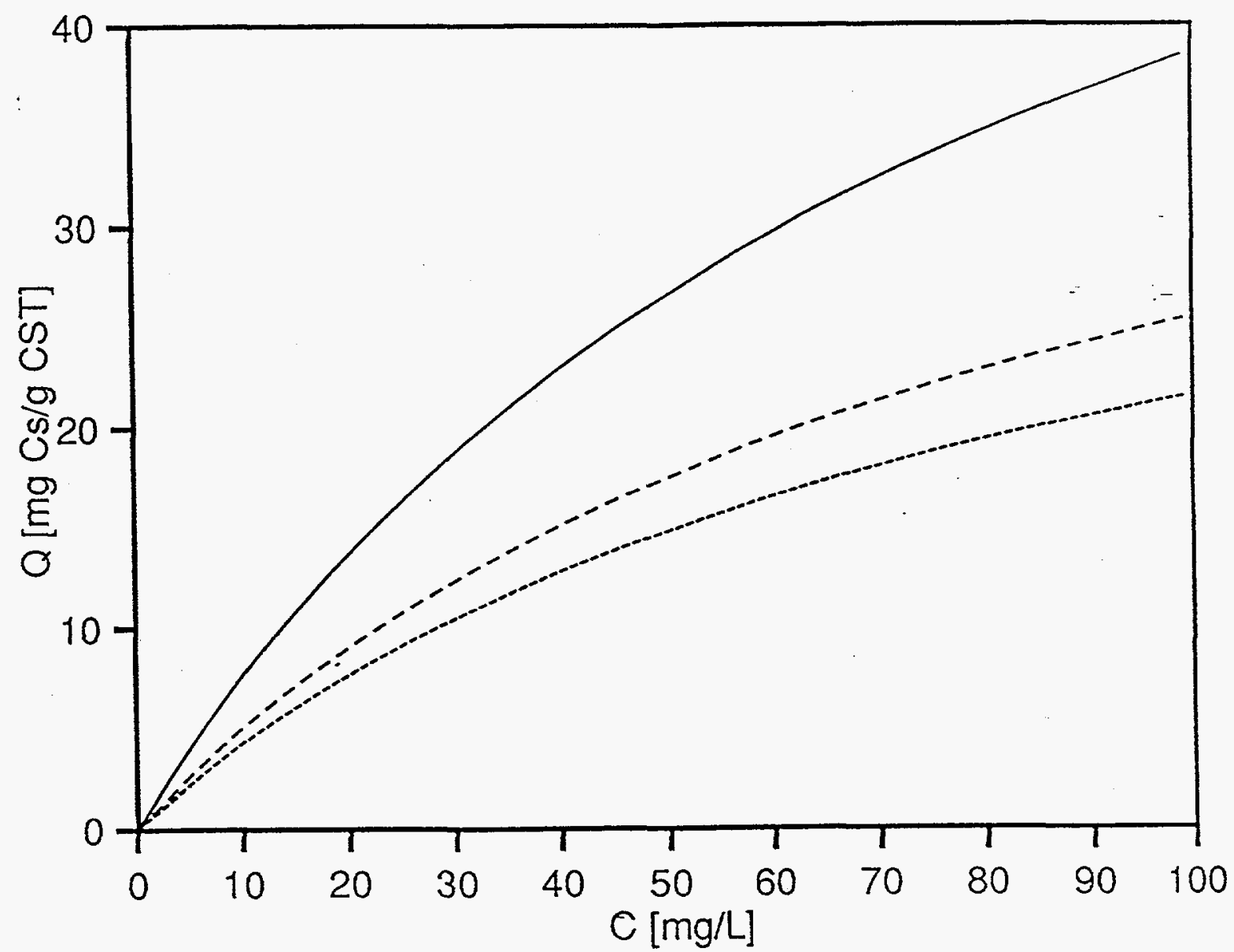

- MVST29 (Jacob

-- - Fit (upper)

-.--- Fit (lower)

Figure 4: $\mathrm{Cs}^{+} / \mathrm{CST}$ isotherm. The solid line denotes the TAMU model of $\mathrm{Cs}^{+}$uptake on powdered CST in MVST-29 waste. The dashed lines represent the upper and lower bounds of isotherms which predict column data on engineered CST in MVST-29 waste. 


\section{APPENDIX A (continued)}

Table 2: Langmuir coefficients, modified from the TAMU model isotherms for SRS wastes. The parameter $a$ has been multiplied by a dilution factor of 0.7 .

\begin{tabular}{lrr}
\hline SRS waste description & $a[\mathrm{~mL} / \mathrm{mL}$ B.V.] & $b[\mathrm{~mL} / \mathrm{mg}]$ \\
\hline Average & 1680 & 30.9 \\
Average, bounding & 1070 & 19.8 \\
High OH & 2030 & 37.6 \\
High OH, bounding & 1370 & 25.3 \\
High $\mathrm{NO}_{3}$ & 1420 & 26.3 \\
High $\mathrm{NO}_{3}$, bounding & 899 & 16.7 \\
\hline
\end{tabular}

experimental data. It was found that the breakthrough times were well predicted when the isotherm parameters for W29 from the TAMU model were adjusted by a factor of 0.56 to 0.66 . These results also indicate the effective $\mathrm{Cs}^{+}$isotherm approach is successful in predicting Cs breakthrough in a complex mixture. The intraparticle diffusivity, $D_{p}$, was then fit to the small-scale frontal data, and the correlation was quite good. Figures 5a-c show the comparison of experimental data to simulation results for small scale CsRD support runs by D. Lee. These parameters were then used to predict the large-scale frontal data, and it was found that the large scale breakthrough curves were slightly more spread than predicted. Figures 6 and 7 show the comparison of experiment to simulation for large scale CsRD column experiments. This indicates that perhaps dispersion in the large columns is greater than that in small columns.

Since MVST waste has a viscosity of $1.6 \mathrm{cp}$ and the SRS waste has a viscosity of $2.2 \mathrm{cp}$, the value of $D_{p}$ determined from the CsRD column tests is not valid for designing columns to handle SRS waste. The Stokes-Einstein equation relates the diffusivity to the solution viscosity:

$$
D=\frac{k_{B} T}{6 \pi \mu R_{0}}
$$

where $D$ is the diffusivity, $k_{B}$ is Boltzmann's constant, $T$ is absolute temperature, $\mu$ is the viscosity, and $R_{0}$ is the solute radius. The value of the diffusivity is inversely proportional to the fluid viscosity, so that the intraparticle diffusivity for SRS wastes is estimated to be

$$
1.0 \times 10^{-4}\left(\frac{1.6}{2.2}\right)=7.3 \times 10^{-5} \mathrm{~cm}^{2} / \mathrm{min}
$$

In order to obtain a conservative design, we were advised to use a lower $D_{p}$ value of $5.0 \times$ $10^{-5} \mathrm{~cm}^{2} / \min [3]$.

\subsection{Column Parameters}

The particle size, interparticle void fraction $\left(\varepsilon_{b}\right)$, and intraparticle void fraction $\left(\varepsilon_{p}\right)$ were based on the known densities of the CST particles [3]. In the mathematical model, it is assumed that all the particles are spherical and of uniform size ( $375 \mu \mathrm{m}$ in diameter $)$. Table 3 lists the simulation parameters. These mass transfer and system parameters have been employed to design large scale carousel processes for treating SRS wastes. 


\section{APPENDIX A (continued)}
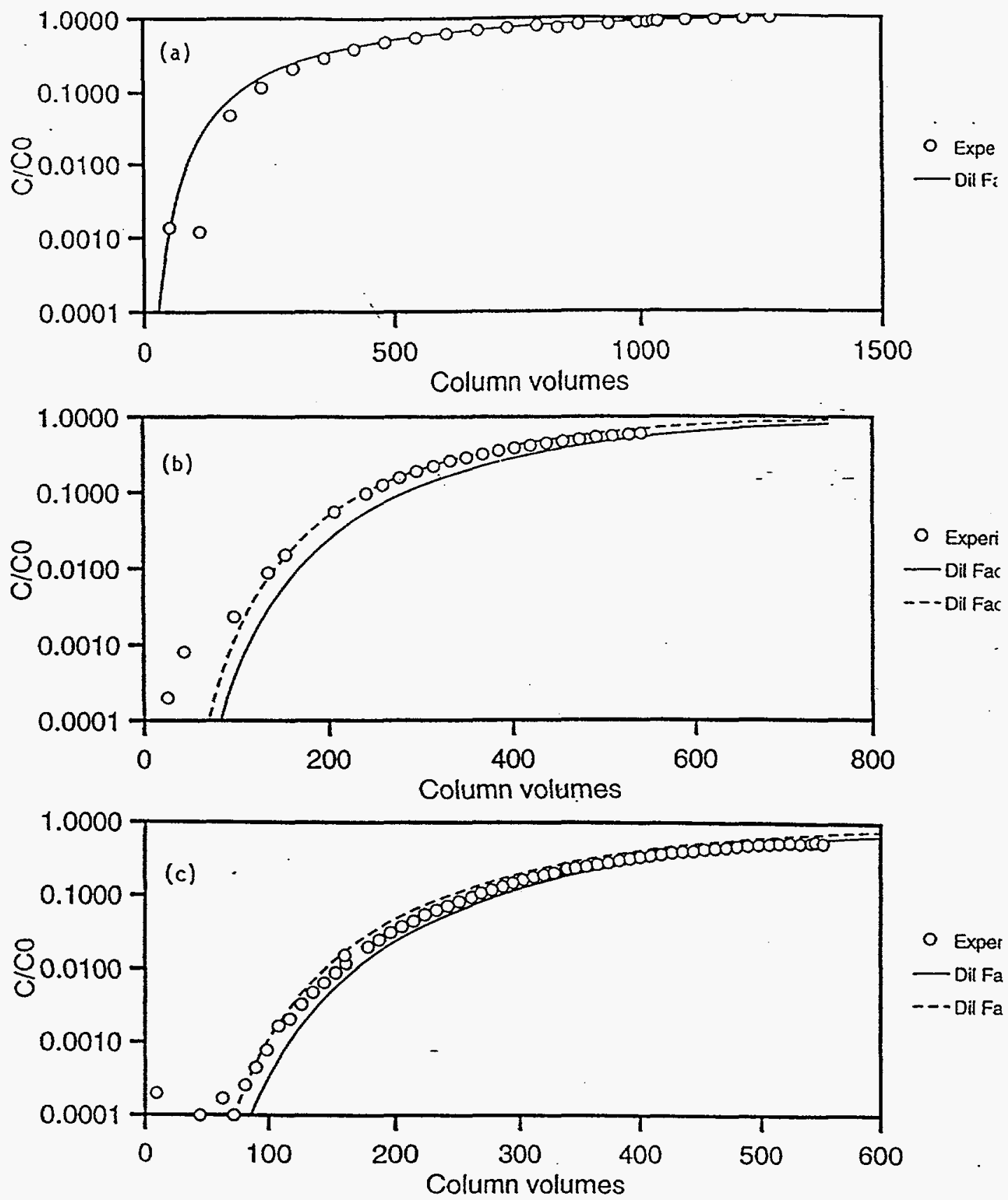

Figure 5: CsRD support column experiments compared to simulation. $D_{p}=1.0 \times 10^{-4}$ $\mathrm{cm}^{2} / \mathrm{min}$. (a) $V_{c}=10.0 \mathrm{~mL}$; I. D. $=1.45 \mathrm{~cm} ; F=1.00 \mathrm{~mL} / \mathrm{min}$. (b) $V_{c}=12.54 \mathrm{~mL}$; I. D. $=1.45 \mathrm{~cm} ; F=0.627 \mathrm{~mL} / \mathrm{min}$. (c) $V_{c}=23.2 \mathrm{~mL}$ total; I. D. $=1.45 \mathrm{~cm} ; F=1.16 \mathrm{~mL} / \mathrm{min}$. 
APPENDIX A (continued)

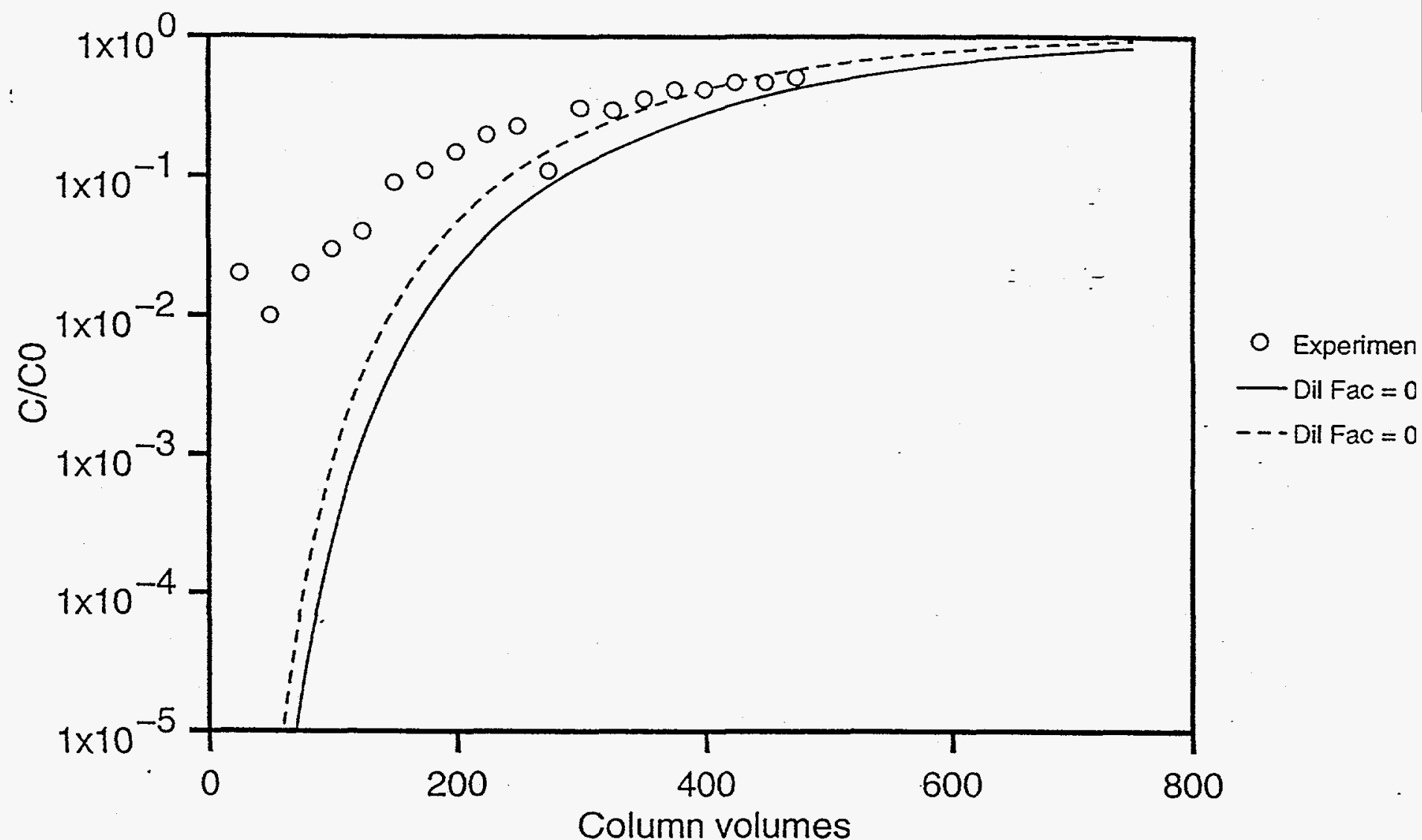

Figure 6: CsRD column experiment compared to simulation. Isotherms are estimated by multiplying TAMU model prediction by 0.56 and 0.66 . Column volume: $38 \mathrm{~L}$. Column diameter: $30 \mathrm{~cm}$. Flow rate: $1.9 \mathrm{~L} / \mathrm{min} . D_{p}=1.0 \times 10^{-4} \mathrm{~cm}^{2} / \mathrm{min}$. 
APPENDIX A (continued)
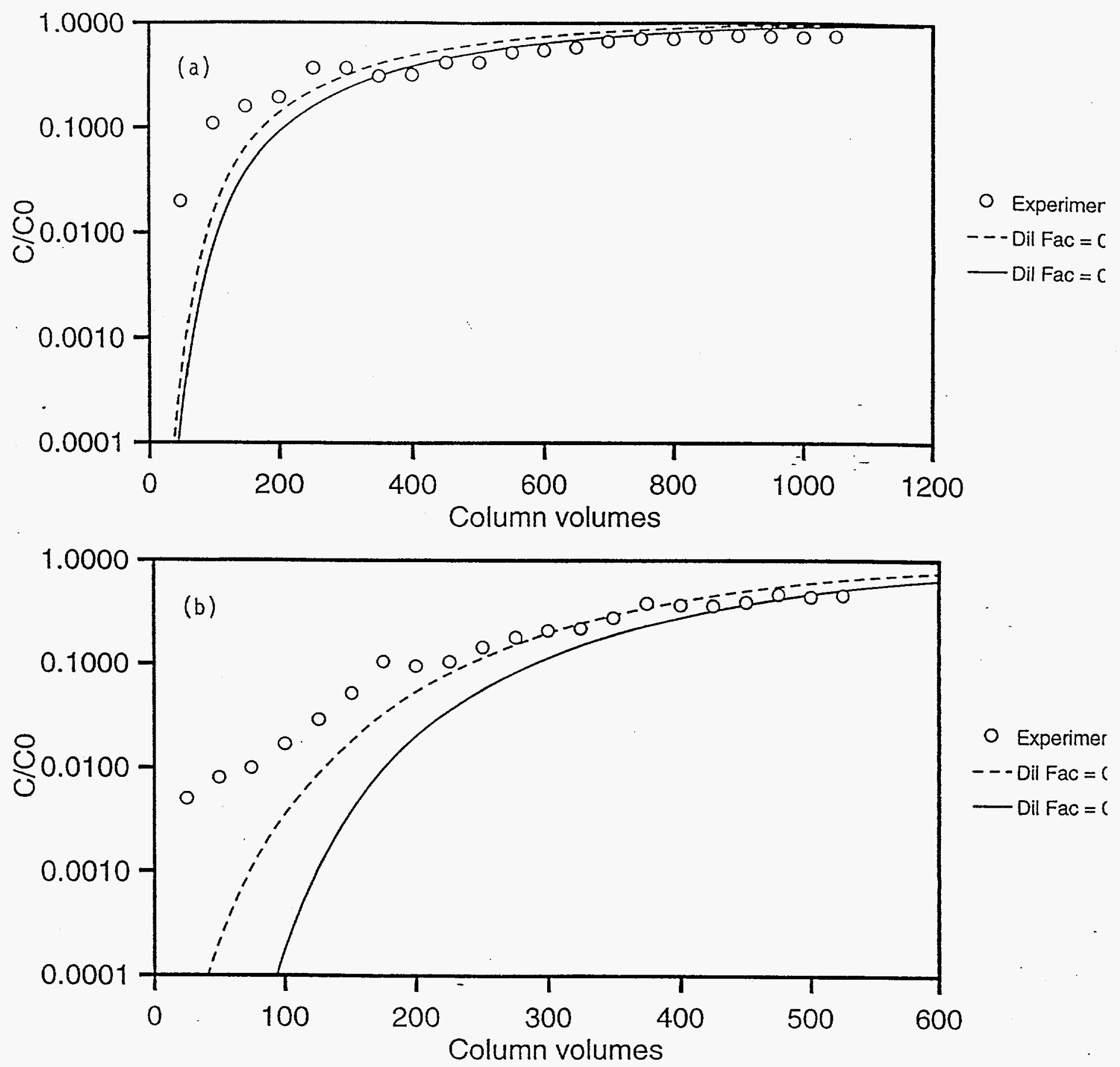

Figure 7: CsRD two-column experiment compared to simulation. Isotherm is estimated by multiplying TAMU model prediction by 0.56 and 0.66 . (a) Lead column effluent history. (b) Second column effluent history. Column volume: $38 \mathrm{~L}$ (each column). Column diameter: 30 cm. Flow rate: $3.8 \mathrm{~L} / \mathrm{min} . D_{p}=1.0 \times 10^{-4} \mathrm{~cm}^{2} / \mathrm{min}$. 


\section{APPENDIX A (continued)}

Table 3: Mass transfer and system parameters used in carousel simulations.

\begin{tabular}{llll}
\hline Parameter & Value, $15 \mathrm{gpm}$ & Value, $25 \mathrm{gpm}$ & Source \\
\hline I. D. [ft] & 4.0 & 5.2 & \\
$R_{p}[\mu \mathrm{m}]$ & 187.5 & 187.5 & McCabe [10] \\
$\varepsilon_{b}[-]$ & 0.50 & 0.50 & Anthony [3] \\
$\varepsilon_{p}[-]$ & 0.24 & 0.24 & Anthony [3] \\
$D_{\infty}\left[\mathrm{cm}^{2} / \mathrm{min}\right]$ & $6.44 \times 10^{-4}$ & $6.44 \times 10^{-4}$ & Ernest et al. [6] \\
$D_{p}\left[\mathrm{~cm}^{2} / \mathrm{min}\right]$ & $5.0 \times 10^{-5}$ & $5.0 \times 10^{-5}$ & Anthony [3] \\
$k_{f}[\mathrm{~cm} / \mathrm{min}]$ & 0.245 & 0.246 & Wilson-Geankoplis [15] \\
$E_{b}\left[\mathrm{~cm}^{2} / \mathrm{min}\right]$ & 0.883 & 0.883 & Chung-Wen [5] \\
\hline
\end{tabular}

\section{Design Approach}

The first step in the design is to determine the mass transfer zone length, which is related to the length of each column in a carousel process. The mass transfer zone length is examined at two different flow rates- 15 and $25 \mathrm{gpm}$, which correspond to two different superficial velocities ( 4.9 and $8.1 \mathrm{~cm} / \mathrm{min}$, respectively). Since the isotherm is nonlinear at the concentration level in the SRS waste (Figure 2), the concentration waves eventually develop into a constant pattern. A sufficiently long column $(66 \mathrm{ft})$ is chosen in this simulation so that the waves can reach a constant pattern. Figures $8 \mathrm{a}-\mathrm{b}$ show the mass transfer zone length determination. The length of the mass transfer zone is determined from the concentration profile where the local concentration decreases from 90 percent of the feed concentration. The feed compositions are listed in Table 4. Notice that the concentration of $\mathrm{Cs}^{+}$varies from waste to waste. For this specification, the percent saturation in the lead column is much higher than 90 percent (the target for Task 4). Clearly, the mass transfer zone length, $L_{\mathrm{MTZ}}$, increases on increasing column length and reaches a maximum value when a constant pattern develops.

If one chooses the constant pattern $L_{\mathrm{MTZ}}$, the carousel design is straightforward. A three segment carousel will have a total length of $3 L_{\mathrm{MTZ}}$. The choice of constant pattern $L_{\mathrm{MTZ}}$ to be the column length will ensure that when the carousel operation reaches cyclic steady state, the percent sorbent utilization in the lead column (saturation zone) will satisfy the percent utilization desired. This is confirmed by VERSE simulations and an example is shown in Figure 10. Table 5 compares the carousel designs at two different linear velocities.

Table 6 lists the column length requirements for three nominal SRS feeds when the column diameter is fixed at $4 \mathrm{ft}$ and the dilution factor is set to 0.7 . For each isotherm, we have determined the mass transfer zone length for two flow rates (15 gpm and $25 \mathrm{gpm}$ ). Because the design is very sensitive to both the isotherm and mass transfer parameters, these values need to be determined accurately.

It is shown in this study that the length of the mass transfer zone is directly proportional to the linear velocity and the square of the particle radius and that it is inversely proportional to the intraparticle diffusivity. These relationships can be summarized by deffining the 


\section{APPENDIX A (continued)}
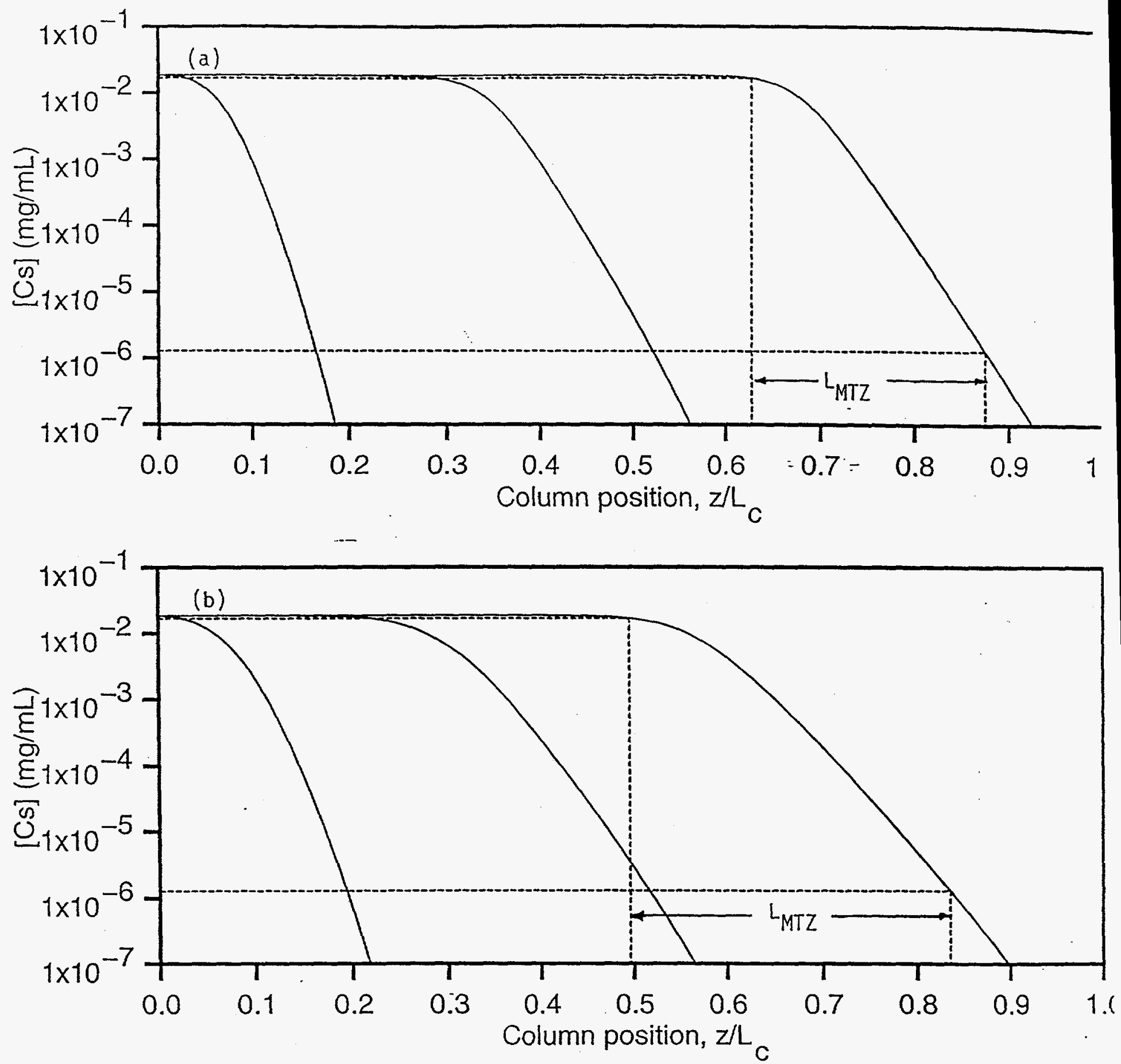

Figure 8: Mass transfer zone length determination for cesium in average SRS waste (nominal). Column diameter: $4 \mathrm{ft}$. Column length: $66 \mathrm{ft}$. Dilution factor: 0.7. $L_{\mathrm{MTZ}}$ determined from the profile where the concentration decreases from $C / C_{0}=0.9$ to $C=1.3 \times 10^{-3}$ mg $/$ L. (a) $F=15$ gpm. $u_{s}=4.9 \mathrm{~cm} / \mathrm{min}$. (b) $F=25 \mathrm{gpm}$. $u_{s}=8.1 \mathrm{~cm} / \mathrm{min}$. 
WSRC-TR-98-00343 Rev.0

Page 23 of 69

\section{APPENDIX A (continued)}

Table 4: SRS waste compositions.

\begin{tabular}{ccccccc}
\hline & \multicolumn{7}{c}{ Concentration [mol/L] } \\
\cline { 2 - 7 } Component & $\mathrm{Avg}$ & $\mathrm{Avg}-\mathrm{b}$ & $\mathrm{OH}$ & $\mathrm{OH}-\mathrm{b}$ & $\mathrm{NO}_{3}$ & $\mathrm{NO}_{3}-\mathrm{b}$ \\
\hline $\mathrm{Na}^{+}$ & 5.6 & 5.47 & 5.6 & 5.48 & 5.6 & 5.45 \\
$\mathrm{~K}^{+}$ & 0.015 & 0.15 & 0.03 & 0.15 & 0.0041 & 0.15 \\
$\mathrm{Cs}^{+}$ & 0.00014 & 0.0007 & 0.00037 & 0.0007 & 0.00014 & 0.0007 \\
$\mathrm{AlO}_{2}^{-}$ & 0.31 & 0.31 & 0.27 & 0.27 & 0.32 & 0.32 \\
$\mathrm{C}_{2} \mathrm{O}_{4}^{-}$ & 0.008 & 0.008 & 0.008 & 0.008 & 0.008 & 0.008 \\
$\mathrm{CO}_{3}^{2-}$ & 0.16 & 0.16 & 0.17 & 0.17 & 0.16 & 0.16 \\
$\mathrm{MoO}_{4}^{2-}$ & 0.0002 & 0.0002 & 0.0002 & 0.0002 & 0.0002 & 0.0002 \\
$\mathrm{SiO}_{3}^{2-}$ & 0.004 & 0.004 & 0.004 & 0.004 & 0.004 & 0.004 \\
$\mathrm{SO}_{4}^{2-}$ & 0.15 & 0.15 & 0.030 & 0.030 & 0.22 & 0.22 \\
$\mathrm{PO}_{4}^{3-}$ & 0.010 & 0.010 & 0.008 & 0.008 & 0.010 & 0.010 \\
$\mathrm{Cl}^{-}$ & 0.025 & 0.025 & 0.010 & 0.010 & 0.040 & 0.040 \\
$\mathrm{~F}^{-}$ & 0.032 & 0.032 & 0.010 & 0.010 & 0.050 & 0.050 \\
$\mathrm{NO}_{2}^{-}$ & 0.52 & 0.52 & 0.74 & 0.74 & 0.37 & 0.37 \\
$\mathrm{NO}_{3}^{-}$ & 2.14 & 2.14 & 1.10 & 1.10 & 2.84 & 2.84 \\
$\mathrm{OH}^{-}$ & 1.91 & 1.91 & 3.05 & 3.05 & 1.17 & 1.17 \\
\hline
\end{tabular}

Table 5: Comparison of three-column carousel processes operated at two different volumetric flow rates. Isotherm is based on SRS average nominal waste with a dilution factor of 0.7 . $D_{p}=5.0 \times 10^{-5} \mathrm{~cm}^{2} /$ min. $R_{p}=187.5 \mu \mathrm{m}$.

\begin{tabular}{lll}
\hline Flow rate [gpm] & 15 & 25 \\
\hline I. D. [ft] & 4.0 & 5.2 \\
Interstitial velocity [cm/min] & 9.7 & 9.7 \\
Superficial velocity [cm/min] & 4.9 & 4.9 \\
$L_{\mathrm{MTZ}}[\mathrm{ft}]$ & 15.6 & 16.0 \\
Total bed volume [ft $\left.{ }^{3}\right]$ & 588 & 1000 \\
Percent column saturation & 99 & 99 \\
Switch time [days] & 72 & 72 \\
\hline
\end{tabular}


APPENDIX A (continued)

Table 6: Case 1. Column length requirement for a fixed column diameter of $4 \mathrm{ft}$. $L_{\mathrm{MTZ}}$ is determined as length of column for concentration to drop from $C / C_{0}=0.9$ to $C=1.3 \times$ $10^{-3} \mathrm{mg} / \mathrm{L}$ at constant pattern. SRS wastes are as defined in Table 4 . The letter $\mathrm{b}$ indicates a high $\mathrm{K}^{+}$(bounding) case. $R_{p}=187.5 \mu \mathrm{m} . D_{p}=5.0 \times 10^{-4} \mathrm{~cm}^{2} / \mathrm{min} . L_{\mathrm{MTZ}}=$ single column length in a three column carousel. $L_{\text {tot }}=3 \times L_{\mathrm{MTZ}}$.

\begin{tabular}{|c|c|c|c|c|c|}
\hline SRS waste & Flow rate [gpm] & $u_{s}[\mathrm{~cm} / \mathrm{min}]$ & $u_{0}[\mathrm{~cm} / \mathrm{min}]$ & $\mathrm{Pe}_{p}$ & $L_{\mathrm{MTZ}}[\mathrm{ft}]$ \\
\hline \multirow{2}{*}{ Average } & 15 & 4.9 & 9.8 & $1.52 \times 10^{5}$ & 15.6 \\
\hline & 25 & 8.1 & 16.2 & $2.53 \times 10^{5}$ & 25.7 \\
\hline \multirow[t]{2}{*}{ Average (b) } & 15 & 4.9 & 9.8 & $1.52 \times 10^{5}$ & 7.5 \\
\hline & 25 & 8.1 & 16.2 & $2.53 \times 10^{5}$ & 12.7 \\
\hline \multirow[t]{2}{*}{ High OH } & 15 & 4.9 & 9.8 & $1.52 \times 10^{5}$ & 7.3 \\
\hline & 25 & 8.1 & 16.2 & $2.53 \times 10^{5}$ & 12.2 \\
\hline \multirow[t]{2}{*}{ High OH (b) } & 15 & 4.9 & 9.8 & $1.52 \times 10^{5}$ & 6.5 \\
\hline & 25 & 8.1 & 16.2 & $2.53 \times 10^{5}$ & 11.1 \\
\hline \multirow[t]{2}{*}{$\mathrm{High} \mathrm{NO}_{3}$} & 15 & 4.9 & 9.8 & $1.52 \times 10^{5}$ & 18.3 \\
\hline & 25 & 8.1 & 16.2 & $2.53 \times 10^{5}$ & 30.5 \\
\hline \multirow[t]{2}{*}{$\mathrm{High} \mathrm{NO}_{3}(\mathrm{~b})$} & 15 & 4.9 & 9.8 & $1.52 \times 10^{5}$ & 8.7 \\
\hline & 25 & 8.1 & 16.2 & $2.53 \times 10^{5}$ & 14.4 \\
\hline
\end{tabular}




\section{APPENDIX A (continued)}

Table 7: Case 2. Column diameter requirement for a fixed column-segment length of $16 \mathrm{ft}$. $R_{p}=187.5 \mu \mathrm{m} . D_{p}=5.0 \times 10^{-5} \mathrm{~cm}^{2} / \mathrm{min}$.

\begin{tabular}{lcccc}
\hline SRS waste & Flow rate $[\mathrm{gpm}]$ & $u_{s}[\mathrm{~cm} / \mathrm{min}]$ & $u_{0}[\mathrm{~cm} / \mathrm{min}]$ & I.D. [ft] \\
\hline Average & 15 & 4.9 & 9.8 & 4.0 \\
& 25 & 4.9 & 9.8 & 5.2 \\
Average (b) & 15 & 10 & 20 & 2.8 \\
& 25 & 10 & 20 & 3.6 \\
High $\mathrm{OH}$ & 15 & 11 & 22 & 2.7 \\
& 25 & 11 & 22 & 3.4 \\
High $\mathrm{OH}(\mathrm{b})$ & 15 & 12 & 24 & \\
& 25 & 12 & 24 & 3.5 \\
High $\mathrm{NO}_{3}$ & 15 & 4.3 & 8.6 & - \\
& 25 & 4.3 & 8.6 & 4.3 \\
& & & & \\
High $\mathrm{NO}_{3}$ (b) & 15 & 9.0 & 18.0 & 2.9 \\
& 25 & 9.0 & 18.0 & 3.8 \\
\hline
\end{tabular}

following dimensionless groups:

$$
\begin{gathered}
L_{\mathrm{MTZ}}^{*} \equiv \frac{L_{\mathrm{MTZ}}}{R_{p}} \\
\mathrm{Pe}_{p} \equiv \frac{u_{0} R_{p}}{D_{p}}
\end{gathered}
$$

where $L_{\mathrm{MTZ}}^{*}$ is the dimensionless mass transfer zone length. Figure 9 shows the relationship between the dimensionless mass transfer zone length and the Peclet number. There is a linear dependence of $L_{\mathrm{MTZ}}^{*}$ on $\mathrm{Pe}_{p}$. It should be pointed out that the slope of the line in each case depends on both the waste type and the cesium concentration. This simple relation can be understood by examining the coefficients of the differential mass balance equations, Equations 3 and 4 . The dimensionless concentration profile or dimensionless mass transfer zone length, $L_{\mathrm{MTZ}}^{*}$, at constant pattern is expected to be a function of the dimensionless groups $\left(L_{c}^{*}, k_{f}^{*}, \phi_{b}, \phi_{p}, \mathrm{Pe}_{p}\right.$, and $\left.\mathrm{Pe}_{b}\right)$. For a sufficiently long column $\left(L_{c} / R_{p}>1000\right)$ at a relatively high linear velocity $\left(u_{0}>0.1 \mathrm{~cm} / \mathrm{min}\right), L_{\mathrm{MTZ}}^{*}$ is controlled by intraparticle diffusion. Therefore, $L_{\mathrm{MTZ}}^{*}$ is only a function of $\mathrm{Pe}_{p}$. If the waste composition remains the same as those in Table 4, Figure 9 provides a convenient estimate of $L_{\mathrm{MTZ}}$ (or carousel size) when $R_{p}, D_{p}$, or $u_{0}$ is varied.

Table 7 lists the required column diameter for a fixed individual column length of $16 \mathrm{ft}$ $\left(L_{\mathrm{MTZ}}=16 \mathrm{ft}\right)$. This implies that $L_{\mathrm{MTZ}}$ is fixed at $16 \mathrm{ft}$ for all the different feeds, whereas the linear velocity $u_{0}$ is varied to achieve this goal. The $u_{0}$ values are determined by finding the Peclet number that gives $L_{\mathrm{MTZ}}=16 \mathrm{ft}$. from Figure 9 for a given SRS waste composition. 
APPENDIX A (continued)

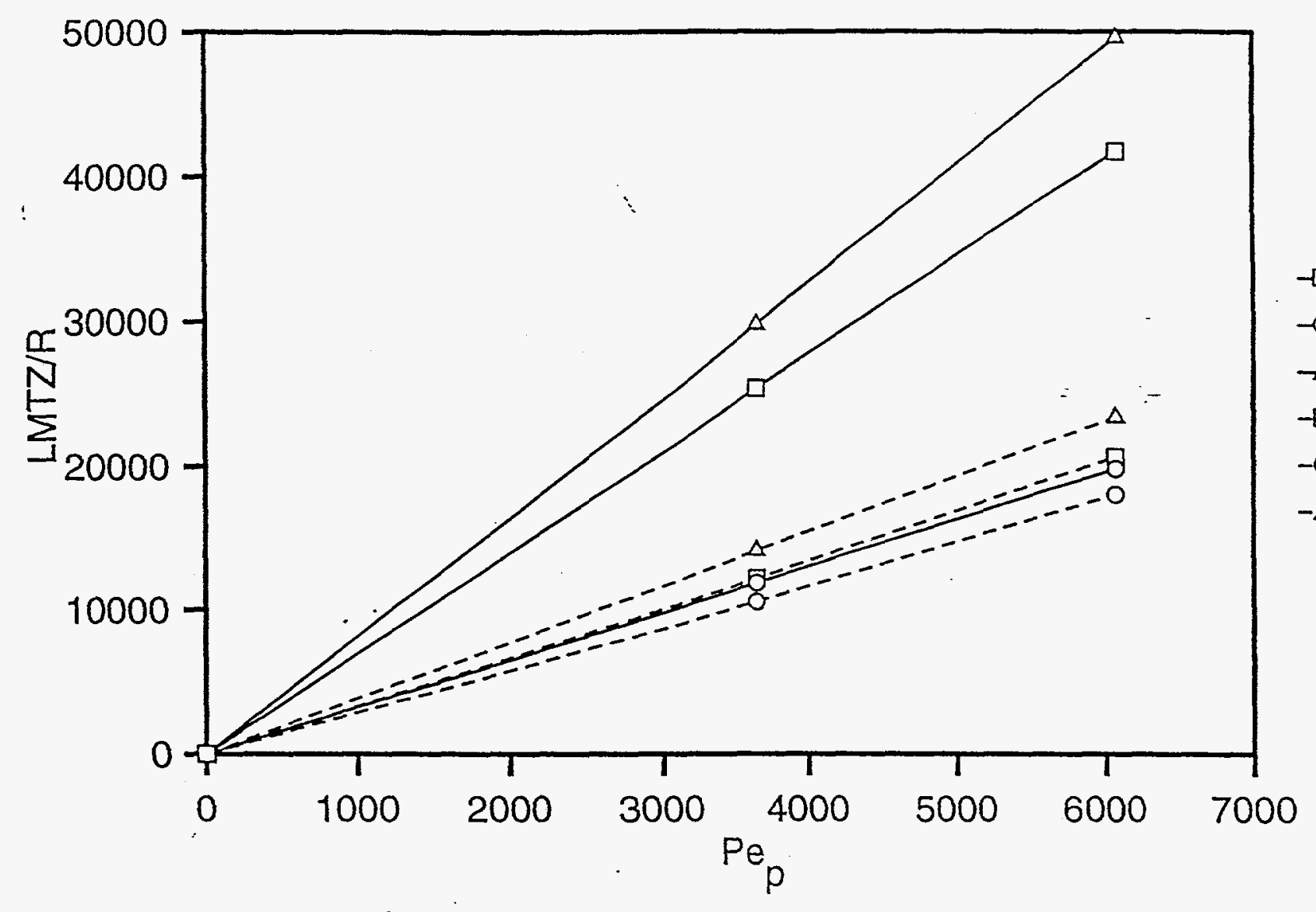

Figure 9: Dimensionless mass transfer zone length as a function of the Peclet number (Equations 7 and 8 ). 


\section{APPENDIX A (continued)}

Column diameters which can handle $15 \mathrm{gpm}$ and $25 \mathrm{gpm}$ are calculated according to a given $u_{0}$. Notice that for a given feed, the linear velocity is the same for 15 and $25 \mathrm{gpm}$. A change in the column diameter allows for a change in the volumetric flow rate.

As clearly shown in Table 6 , the $L_{\mathrm{MTZ}}$ for $4 \mathrm{ft}$ diameter columns for some cases are less than $16 \mathrm{ft}$. Therefore the column diameter in Table 7 can be reduced to below $4 \mathrm{ft}$ and a higher $u_{0}$ can be used. In contrast, for the cases in Table 6 where the $L_{\mathrm{MTZ}}$ are longer than $16 \mathrm{ft}$, a lower $u_{0}$ must be used to confine the mass transfer zone to $16 \mathrm{ft}$, and column diameters must be increased to above $4 \mathrm{ft}$ to accomodate $15 \mathrm{gpm}$ and $25 \mathrm{gpm}$ feed flow rates.

In the carousel process simulations, the port switching occurs when the outlet concentration of the second column reaches $1.3 \times 10^{-3} \mathrm{mg} / \mathrm{L}$. At this time, the first column is taken off-line, the feed is introduced into the second column, and a fresh column introduced at the end of the train (as a guard column). Figure 10 shows the simulated concentration histories at the outlet of each column in a three-column carousel process. Notice that the outlet concentration of column 2 reaches the specified value of $1.3 \times 10^{-3} \mathrm{mg} / \mathrm{L}$ at the port switching time. The outlet concentration of column 3 (the guard column) is too low to be seen in this figure. Figure 1 also shows that cyclic steady state is established after three switching periods. The utilization of the lead column is about 99.6 percent before cyclic steady state is established and 98.8 percent at cyclic steady state. This result proves that by choosing the constant pattern $L_{\mathrm{MTZ}}$, one can ensure that percent utilization is high during the startup and after cyclic steady state is established.

\section{Design Alternatives}

There are many alternative carousel designs that can meet SRS waste treatment requirements. The sizes of the carousel columns in Tables 6 and 7 are estimated based on a fixed diameter for Case 1 and a fixed segment length of $16 \mathrm{ft}$ for Case 2 and the following assumptions: (1) The effective $\mathrm{Cs}^{+}$isotherms of the wastes can be predicted by using the TAMU model with a dilution factor of 0.7 . (2) The $D_{p}$ value is $5.0 \times 10^{-5} \mathrm{~cm}^{2} / \mathrm{min}$ for all wastes. (3) The $L_{\mathrm{MTZ}}$ is defined as the length where $C$ decreases from $0.9 C_{0}$ to $1.3 \times 10^{-3} \mathrm{mg} / \mathrm{L}$. This definition gives a percent utilization of 99.6 during the startup and 98.8 percent at cyclic steady state. One can choose a shorter $L_{\mathrm{MTZ}}$ if a lower percent utilization of the lead column is desired or the level of $\mathrm{Cs}^{+}$in the effluent of column 2 can be higher than $1.3 \times$ $10^{-3} \mathrm{mg} / \mathrm{L}$. (4) The current design assumes three columns: the lead column is for saturation; the second column is to contain the mass transfer zone; and the third column is a guard column. Each column length is the same as the mass transfer zone length.

Alternatively, the mass transfer zone can be spread among two columns, thus halving the size of the lead column and the guard column in the process. The saturation zone and the guard zone decrease in length, while the mass transfer zone remains fixed, leading to a shorter overall bed length. Table 8 compares the performances of carousel processes with three, four, five, and six column segments. One can see that there is a 50 percent gain in the throughput per bed volume and a 33 percent decrease in the bed length on increasing the number of segments from three to four. However, there is also a 50 percent smaller guard column and one more valve. These factors need to be taken into account in process optimization in the future. 


\section{APPENDIX A (continued)}

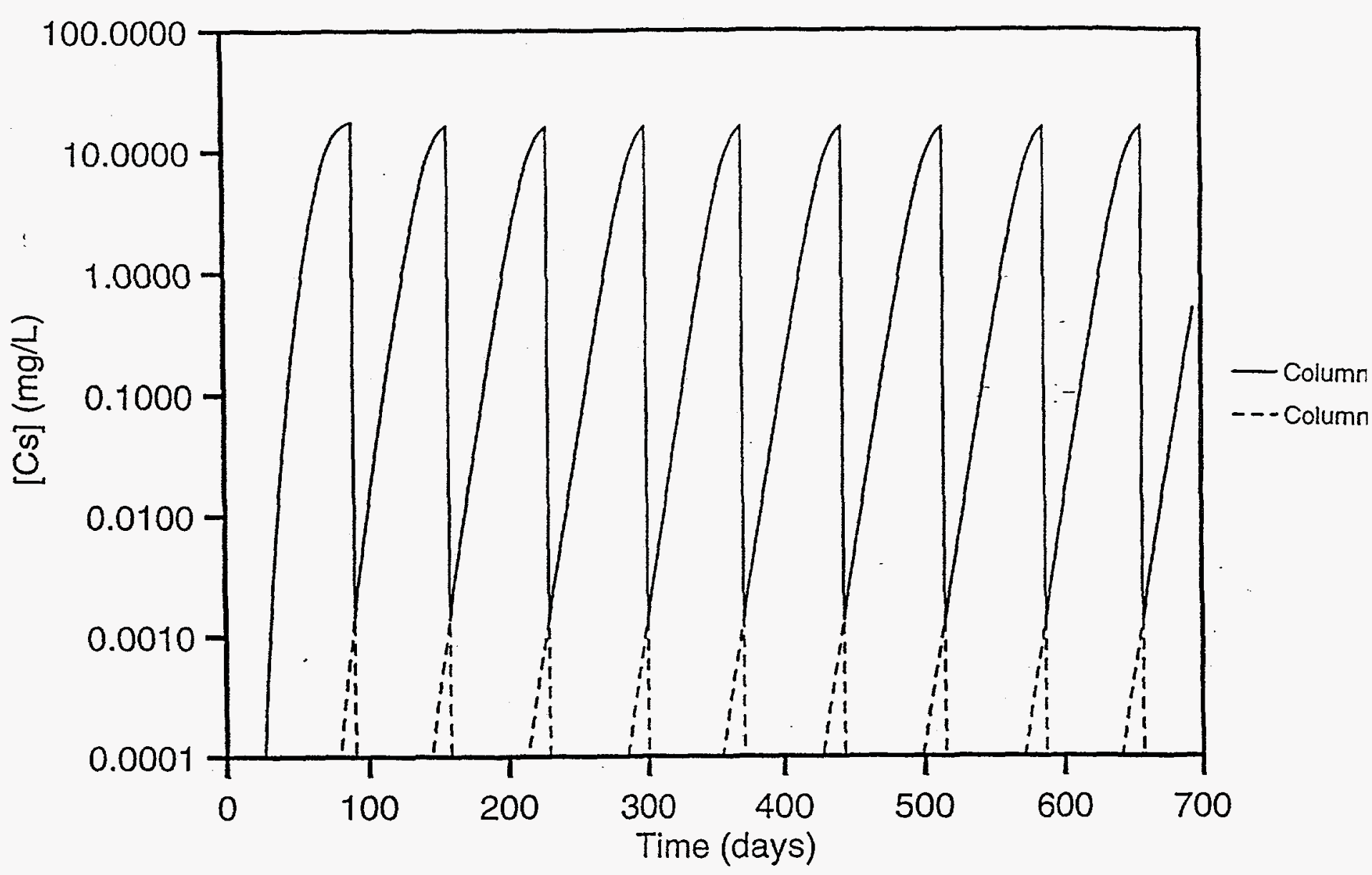

Figure 10: Simulated $\mathrm{Cs}^{+}$concentration histories at each outlet port in a three-column carousel process. Feed: average SRS. Dilution factor: 0.7. Total bed length: $46.8 \mathrm{ft}$. Flow rate: $15 \mathrm{gpm} . D_{p}=5.0 \times 10^{-5} \mathrm{~cm}^{2} / \mathrm{min}$. Saturation of lead column: 99 percent. Solid line: lead column history. Dashed line: second column history. The outlet concentration of the third column is below $10^{-7} \mathrm{mg} / \mathrm{mL}$. 


\section{APPENDIX A (continued)}

Table 8: Comparison of carousel configurations with varying numbers of segments. Column cross-sectional area and flow rate are fixed.

\begin{tabular}{lllll}
\hline $\begin{array}{l}\text { Number of } \\
\text { segments }\end{array}$ & Total bed length & Relative TPBV & $\begin{array}{l}\text { Guard column } \\
\text { length }\end{array}$ & $\begin{array}{l}\text { Number of } \\
\text { valves }\end{array}$ \\
\hline 3 & $3 L_{\mathrm{MTZ}}$ & 1 & $L_{\mathrm{MTZ}}$ & 3 \\
4 & $2 L_{\mathrm{MTZ}}$ & 1.5 & $0.50 L_{\mathrm{MTZ}}$ & 4 \\
5 & $1.67 L_{\mathrm{MTZ}}$ & 1.8 & $0.33 L_{\mathrm{MTZ}}$ & 5 \\
6 & $1.5 L_{\mathrm{MTZ}}$ & 2.0 & $0.25 L_{\mathrm{MTZ}}$ & 6 \\
\hline
\end{tabular}

\section{Conclusions}

A model-based approach has been developed to design a CST carousel ion exchange process for removing cesium from Savannah River Site wastes. Batch equilibrium data were correlated using a detailed ion exchange model for CST powder (TAMU model). The model predictions were then fit to the Langmuir equation to obtain effective cesium isotherms for six model SRS waste compositions. A dilution factor of 0.7 was used in order to fit the isotherm to column data and to account for the presence of an inert binder in CST pellets. This effective cesium isotherm approach was validated using the data from both small-scale and large-scale column tests obtained for ORNL wastes. Axial dispersion and film mass transfer coefficients were calculated from well-known correlations, and the intraparticle diffusivity was determined by fitting porous model predictions to ORNL column data. These mass transfer parameters were validated over a wide range of linear velocities for the W29 wastes.

In the design of the carousel process, the length of a single column segment is determined from the length of the mass transfer zone at a given linear velocity. The mass transfer zone is defined as the length of column required to contain the $\mathrm{Cs}^{+}$concentration band from $C$ $=0.9 C_{0}$ to $C=1.3 \times 10^{-3} \mathrm{mg} / \mathrm{L}$ after the development of a constant pattern wave. An analysis of the dimensionless groups reveals that the normalized mass transfer zone length is proportional to the particle Peclet number. The proportionality constant is a function of the waste composition and the $\mathrm{Cs}^{+}$concentration. For a given composition, modifications of a given design can be easily made by the use of this simple linear relation.

This study shows that the estimated carousel sizes are most sensitive to the effective cesium isotherms and the intraparticle diffusivities. The bed void fraction also has a direct impact on the size estimates. Accurate estimates of these key parameters should be the major goals of future batch and column tests for the various SRS wastes.

\section{Acknowledgment}

The authors wish to thank Mr. Walter Tamosaitis and Mr. C. Phillip McGinnis for initiating this project. The authors acknowledge Dr. Darrel Doug Walker, Dr. Scott Beck, and Mr. Joe Carter for providing background information; Mr. Roy Jacobs for calculating $\mathrm{Cs}^{+}$isotherms from the TAMU model; Professor Ray Anthony for providing the TAMU model as well as 


\section{APPENDIX A (continued)}

many system parameters; Dr. Dan McCabe for providing SRS simulant batch data; and Dr. Doug Lee and Mr. Paul Taylor for providing W29 column data.

\section{Nomenclature}

$a=$ Langmuir coefficient, $\mathrm{mg} / \mathrm{mL}$ B.V.

$b=$ Langmuir coefficient, $\mathrm{mL} / \mathrm{mg}$

$C=$ bulk-phase solute concentration, $\mathrm{mg} / \mathrm{mL}$

$C_{p}=$ pore-phase solute concentration, $\mathrm{mg} / \mathrm{mL}$

$C_{0}=$ column inlet solute concentration, $\mathrm{mg} / \mathrm{mL}$

$D=$ diffusivity, $\mathrm{cm}^{2} / \mathrm{min}$

$D_{p}=$ intraparticle diffusivity, $\mathrm{cm}^{2} / \mathrm{min}$

$D_{\infty}=$ Brownian diffusivity, $\mathrm{cm}^{2} / \mathrm{min}$

$E_{b}=$ axial dispersion coefficient, $\mathrm{cm}^{2} / \mathrm{min}$

$F=$ volumetric flow rate, $\mathrm{gpm}$ or $\mathrm{mL} / \mathrm{min}$

I. D. = column inner diameter, $\mathrm{ft}$

$k_{B}=$ Boltzmann's constant; $4.97 \times 10^{-13} \mathrm{~g} \cdot \mathrm{cm}^{2} / \mathrm{K} \cdot \mathrm{min}^{2}$

$k_{f}=$ film mass transfer coefficient, $\mathrm{cm} / \mathrm{min}$

$L_{c}=$ column length, $\mathrm{cm}$ or $\mathrm{ft}$

$q=$ solid-phase solute concentration, $\mathrm{mg} / \mathrm{mL} \mathrm{S.V.}$

$r=$ radial distance from center of adsorbent particle, $\mathrm{cm}$

$R_{0}=$ solute radius, $\mathrm{cm}$

$R_{p}=$ adsorbent particle radius, $\mathrm{cm}$ or $\mu \mathrm{m}$

$t=$ time, $\min$

$T=$ absolute temperature, $\mathrm{K}$

$\mathrm{TPBV}=$ throughput per bed volume, $\mathrm{gpm} / \mathrm{ft}^{3}$

$u_{0}=$ linear interstitial velocity, $\mathrm{cm} / \mathrm{min}$

$u_{s}=$ linear superficial velociey, $\mathrm{cm} / \mathrm{min}$

$V_{c}=$ column volume, $\mathrm{mL}$ or $\mathrm{L}$

$z=$ axial distance, $\mathrm{cm}$

Greek Symbols

$\varepsilon_{b}=$ bed void fraction, dimensionless

$\varepsilon_{p}=$ intraparticle void fraction, dimensionless

$\mu=$ solution viscosity, $\mathrm{g} / \mathrm{cm} \cdot \mathrm{min}$

Dimensionless Variables

$k_{f}^{*}=k_{f} / u_{0}$ (film mass transfer number)

$L_{c}^{*}=L_{c} / R_{p}$ (dimensionless column length)

$L_{\mathrm{MTZ}}^{*}=L_{\mathrm{MTZ}} / R_{p}$ (dimensionless mass transfer zone length)

$\mathrm{Pe}_{b}=u_{0} L_{c} / E_{b}$ (bulk Peclet number)

$\mathrm{Pe}_{p}=u_{0} R_{p} / \epsilon_{p} D_{p}$ (particle Peclet number)

$x=z / L_{c}$ (dimensionless axial position)

$\theta=t u_{0} / L_{c}$ (dimensionless time) 


\section{APPENDIX A (continued)}

$\xi=r / R_{p}$ (dimensionless radial position)

$\phi_{b}=\left(1-\varepsilon_{b}\right) / \varepsilon_{b}$ (particle/bulk phase ratio)

$\phi_{p}=\left(1-\varepsilon_{b}\right) / \varepsilon_{b}$ (solid/pore phase ratio)

\section{References}

[1] R. G. Anthony, R. G. Dosch, D. Gu, and C. V. Philip. Use of silicotitanates for removing cesium and strontium from defense waste. Ind. Eng. Chem. Res., 33:2702-2705, 1994.

[2] R. G. Anthony, C. V. Philip, and R. G. Dosch. Selective adsorption and ion exchange of metal cations and anions with silico-titanates and layered titanates. Waste Manage. (N.Y.), 13:503-512, 1993.

[3] R. G. Anthony, Texas A\&M University, personal communication, 1998.

[4] J. A. Berninger, R. D. Whitley, and N.-H. L. Wang. A versatile model for simulation of reaction and nonequilibrium dynamics in multicomponent fixed-bed adsorption processes. Comp. Chem. Eng., 15:749-768, 1991.

[5] S. F. Chung and C. Y. Wen. Longitudinal dispersion of liquid flowing through fixed and fluidized beds. AIChE J., 14:857-866, 1968.

[6] M. V. Ernest Jr., J. P. Bibler, R. D. Whitley, and N.-H. L. Wang. Development of a carousel ion exchange process for removal of cesium-137 from alkaline nuclear waste. Ind. Eng. Chem. Res., 36:2775-2788, 1997.

[7] J.-H. Koh, P. C. Wankat, and N.-H. L. Wang. Pore and surface diffusion and bulk-phase mass transfer in packed and fluidized beds. Ind. Eng. Chem. Res., 37:228-239, 1998.

[8] D. D. Lee, J. F. Walker Jr., P. A. Taylor, and D. W. Hendrickson. Cesium-removal flow studies using ion exchange. Environ. Prog., 16:251-262, 1997.

[9] Z. Ma, R. D. Whitley, and N.-H. L. Wang. Pore and surface diffusion in multicomponent adsorption and liquid chromatography systems. AIChE J., 42:1244-1262, 1996.

[10] D. J. McCabe. Crystalline silicotitanate examination results. Technical Report WSRCRP-94-1123, Westinghouse Savannah River Company, Aiken, SC, May 1995.

[11] D. J. McCabe. Examination of crystalline silicotitanate applicability in removal of cesium from SRS high level waste. Technical Report WSRC-TR-97-0016, Westinghouse Savannah River Company, Aiken, SC, April 1997.

[12] C. P. McGinnis, R. D. Hunt, S. M. Gibson, and R. L. Gilchrist. Separation projects within the U. S. Department of Energy's Underground Storage Tank-Integrated Demonstration. Sep. Sci. Tech., 30:1741-1754, 1995. 


\section{APPENDIX A (continued)}

[13] J. F. Walker Jr., P. A. Taylor, R. L. Cummins, B. S. Evans, S. D. Heath, J. D. Hewitt, R. D. Hunt, H. L. Jennings, J. A. Kilby, D. D. Lee, S. Lewis-Lambert, S. A. Richardson, and R. F. Utrera. Cesium removal demonstration utilizing crystalling silicotitanate sorbent for processing Melton Valley Storage Tank supernate: Final report. Technical Report ORNL/TM-13503, Oak Ridge National Laboratory, Oak Ridge, TN, March 1998.

[14] R. D. Whitley. Dynamics of Nonlinear Multicomponent Chromatography-Interplay of Mass Transfer, Intrinsic Sorption Kinetics, and Reaction. PhD thesis, Purdue University, 1990.

[15] E. J. Wilson and C. J. Geankòplis. Liquid mass transfer at very low Reynolds numbers in packed beds. Ind. Eng. Chem. Fundam., 5:9-14, 1966.

[16] Z. Zheng, R. G. Anthony, and J. E. Miller. Modeling multicomponent ion exchange equilibrium utilizing hydrous crystalline silicotitanates by a multiple interactive ion exchange site model. Ind. Eng. Chem. Res., 36:2427-2434, 1997. 
APPENDIX B

Texas A\&M Report

\title{
Treating Savannah River Waste Using UOP IONSIV IE911
}

\author{
M. E. Huckman, I. M. Latheef, R. G. Anthony \\ Texas A\&M University, College Station, TX, 77843-3122 \\ Department of Chemical Engineering \\ Kinetics, Catalysis, and Reaction Engineering Group
}


WSRC-TR-98-00343 Rev.0

Page 34 of 69

APPENDIX B (continued)

\title{
Treating Savannah River Waste Using UOP IONSIV IE911
}

\author{
M. E. Hucknan, I. M Latheef, R. G. Anthony \\ Texas A\&M Untiversity, College Station, $2 X, 77843-3122$ \\ Department of Chemical Engineering \\ Kinetics, Catalysis, and Reaction Engineering Group
}

September 24, 1998

\section{Executive Summary}

Designs for treating Savannah River Tank Waste in a two-column ion exchange carousel using UOP IONSTV IE9II are presented. The design exercise was conducted for three waste compositions, two flow rates, and two design cases. The wastes were labeled-Avg, HiNO, and $\mathrm{HiOH}$, the flow rates were $15 \mathrm{gpm}$ and $25 \mathrm{gpm}$, and the two design cases werc as follows:

Case 1) With the column diameter fixed at four feet, determine the nocessary column length for a two column carousel system. Parallel trains of columns can be used if necessary.

Case 2) With individual column lengths fixed at 16 foct, determine the necessary column diameter (maximum diameter is eight feet) for a two column carousel system. Parallel trains of columns can be used if necessary.

The design specifications for the carouscl were that the $\mathrm{Cs}^{+}$concentration in the effluent from the First column be $90 \%$ of the feed concentration, when the concentration in the effluent from second column reaches $1.3 \mathrm{ppb}\left(\mathrm{mg} / \mathrm{m}^{3}\right.$ or $\left.20 \mathrm{nCi} / \mathrm{g}\right)$. The design information for Case 1 and Case 2 arc summarized in Tables 1 and 2, respectively.

The design cases were evaluated using an effective diffusivity of $0.2 \times 10^{-10} \mathrm{~m}^{2} / \mathrm{s}$. We consider this a conscrvative cstimale. Column experiments are currently underway al SRS to measure breakthrough curves using solutions representative of SRS waste. These experimental data can , and should, be used to fine-tune the estimate for the effective diffiusivity.

A. case study is presented which demonstrates that, over the range of superficial velocities being considcred by SRS, the superficial velocity has a negligible effoct on the column breakthrough profile when the space velocity is held constant. This result necessarily implies that the column concentration profile is unaffected by superficial velocity when it is plotted as concentration versus volume instead of concentration versus length and when the space velocity is held constant. Thus, space velocity (or residence time) based on the total volume of the ion exchange bed in the carousel is the natural design variable for this system.

Using space velocity, we constructed design curves for six of the waste compositions provided by Roy Jacobs. The curves are presented in Figure l. They plot the space velocity required to 


\section{APPENDIX B (continued)}

meet the design effluent specifications versus the number of working columns in the carouscl. These curves illustrate two important points:

1. The waste compositions with lower distribution coefficients do not necessarily yield the conservative desigu cases. Also, the bounding compositions do not represent the worst design cases. In terms of space velocity, conservative means a smaller space velocity which translales into a larger carousel for a given flow rate. We strongly recommend that an effort be undertaken to identify the actual worst case compositions and their effect on the design and operation of the carouscl.

2. As the number of columns in the carousel incrcases, the space velocity required to meet the design cffluent spocifications increases. Thus, for a given flow rate, the required total volume of the carousel decreases. We recommend that the number of working columns in the carousel be considered as a design variable.

Table 1. Case 1 designs: The column diameter is lixed at four feet. The design is for twocolumn carousel system with no parallel trains. The lengths are for individual columns. The space velocities (S.V.) are based on the carousel volume.

\begin{tabular}{|c|c|c|c|c|c|c|c|}
\hline Waste & Flow Rate & $\begin{array}{l}\text { Length } \\
\text { (1 col.) }\end{array}$ & $\begin{array}{l}\text { Carous. } \\
\text { Volume }\end{array}$ & $K_{d}$ & S.V. & $\begin{array}{l}\Delta \mathrm{P} / \text { column } \\
\text { (PSD) }\end{array}$ & Sup. Vel. \\
\hline Arg & $15 \mathrm{gpm}$ & $16.3 \mathrm{ft}$ & $412 \mathrm{t}^{3}$ & 1060 & $0.29 \mathrm{~h}^{-1}$ & 5.8 & $4.9 \mathrm{~cm} / \mathrm{min}$ \\
\hline Avg & $25 \mathrm{gpm}$ & $27.2 \mathrm{ft}$ & $686 \mathfrak{A}^{3}$ & 1060 & $0.29 \mathrm{~h}^{-1}$ & 16.5 & $8.1 \mathrm{~cm} / \mathrm{min}$ \\
\hline HiOH & $15 \mathrm{gpm}$ & $3.41 \mathrm{ft}$ & $187 \mathfrak{A t}^{3}$ & 713 & $0.65 \mathrm{~h}^{-1}$ & 2.6 & $4.9 \mathrm{~cm} / \mathrm{min}$ \\
\hline HiOH & $25 \mathrm{gpm}$ & $12.3 \mathrm{ft}$ & $312 \mathrm{ft}^{3}$ & 713 & $0.65 \mathrm{~h}^{-1}$ & 7.4 & $8.1 \mathrm{~cm} / \mathrm{min}$ \\
\hline HiNO & $15 \mathrm{gpm}$ & $18.6 \mathrm{ft}$ & $468 \mathrm{ft}^{3}$ & 953 & $0.26 h^{-1}$ & 6.6 & $4.9 \mathrm{~cm} / \mathrm{min}$ \\
\hline HANO & $25 \mathrm{gpm}$ & $31.0 \mathrm{ft}$ & $780 \mathrm{ft}^{3}$ & 953 & $0.26 h^{-1}$ & 18.8 & $8.1 \mathrm{~cm} / \mathrm{min}$ \\
\hline
\end{tabular}

- Texas A \&cM University - Department of Chemical Enginoering 


\section{APPENDIX B (continued)}

Table 2. Case 2 designs: The column length is fixed at sixteen foet. The design is for twocolumn carousel system with no parallel trains. The space velocities are based on the carousel volume.

\begin{tabular}{cccccccc}
\hline Waste & Flow Rate & Diam. & $\begin{array}{c}\text { Carous. } \\
\text { Volume }\end{array}$ & $\mathrm{K}_{\mathrm{d}}$ & $\mathrm{S} . \mathrm{V}$. & $\begin{array}{c}\Delta \mathrm{P} / \text { column } \\
\text { (PSI) }\end{array}$ & Sup. Vel. \\
\hline Avg & $15 \mathrm{gpm}$ & $\begin{array}{c}4.05 \mathrm{ft} \\
\ddots\end{array}$ & $412 \mathrm{ft}^{3}$ & 1060 & $0.29 \mathrm{~h}^{-1}$ & 5.5 & $4.8 \mathrm{~cm} / \mathrm{min}$ \\
Avg & $25 \mathrm{gpm}$ & $5.22 \mathrm{ft}$ & $686 \mathrm{ft}^{3}$ & 1060 & $0.29 \mathrm{~h}^{-1}$ & 5.5 & $4.8 \mathrm{~cm} / \mathrm{min}$ \\
HiOH & $15 \mathrm{gpm}$ & $2.73 \mathrm{ft}$ & $187 \mathrm{ft}^{3}$ & 713 & $0.65 \mathrm{~h}^{-1}$ & 12.7 & $10.5 \mathrm{~cm} / \mathrm{min}$ \\
HiOH & $25 \mathrm{gpm}$ & $3.52 \mathrm{ft}$ & $312 \mathrm{ft}^{3}$ & 713 & $0.65 \mathrm{~h}^{-1}$ & 12.7 & $10.5 \mathrm{~cm} / \mathrm{min}$ \\
HiNO & $15 \mathrm{gpm}$ & $4.32 \mathrm{ft}$ & $468 \mathrm{f}^{3}$ & 953 & $0.26 \mathrm{~h}^{-1}$ & 4.8 & $4.2 \mathrm{~cm} / \mathrm{min}$ \\
HiNO & $25 \mathrm{gpm}$ & $5.57 \mathrm{ft}$ & $780 \mathrm{f}^{3}$ & 953 & $0.26 \mathrm{~h}^{-1}$ & 4.8 & $4.2 \mathrm{~cm} / \mathrm{min}$ \\
\hline
\end{tabular}

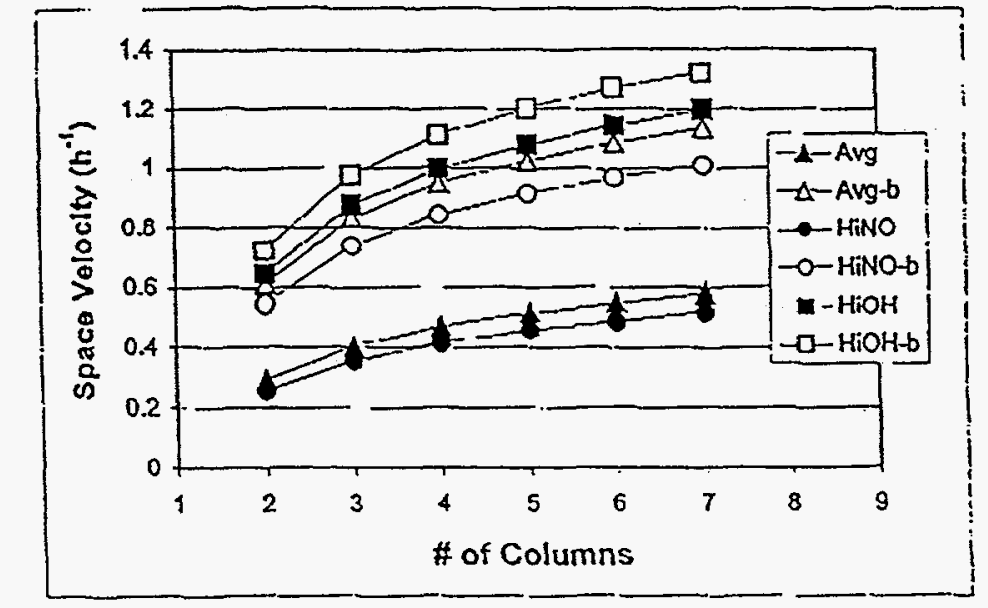

Figure 1. Design curves for various Savannah River wastes. As the number of working columns in the carousel inoreases, the required space velocity increases which, for a fixed flow rate, means a smaller carousel. For a given flow rate, the carousel volumc is found by dividing the flow rate by the space velocity. Individual column volumes are found by dividing the carousel volume by the number of working columns. 


\section{APPENDIX B (continued)}

The four expcriments modeled by Scot Beck and Roy Jacobs as a preliminary design exercise were revisited. The objective was to simulate these experiments using the Texas A\&CM ion exchange column model and then examine the consistency of the modeling parameters. The results of this excrcise are summarized in Table 3. The distribution coefficients used to model all of the experiments were between $60 \%$ and $66 \%$ of the value predicted by the Texas A\&M powder equilibrium model. Three of the experiments, MVST W-29, MVST W-27, and Sandia DSSF5, were modeled using an effective diffusivity of $0.8 \times 10^{-10} \mathrm{~m}^{2} / \mathrm{s}$. The fourth experiment, A.W-101, required effective diffusivity of $2.0 \times 10^{-10} \mathrm{~m}^{2} / \mathrm{s}$. We consider these best-fit parameters to be reasonably consistent.

Table 3. Summary of best fit parameters for four ion exchange column experiments using the Texas A\&M ion exchange column model. Because the $\mathrm{Cs}^{+}$concentrations for these experiments were all less than 10ppm, the experiments were modeled using a linear isotherm.

\begin{tabular}{ccccc}
\hline Experiment & Best fit $K_{d}$ & Predicted $K_{d}$ & Dilution Factor & $D_{\text {closive }}$ \\
\hline Sandia DSSF5 & 575 & 910 & 0.63 & $0.8 \times 10^{-10}$ \\
MVST W-29 & 575 & 950 & 0.61 & $0.8 \times 10^{-10}$ \\
MVST W-27 & 375 & 600 & 0.63 & $0.8 \times 10^{-10}$ \\
Hanford AW-101 & 775 & 1173 & 0.66 & $2.0 \times 10^{-10}$ \\
\hline
\end{tabular}


WSRC-TR-98-00343 Rev.0

Page 38 of 69

APPENDIX B (continued)

\section{Treating Savannah River Waste Using UOP IONSIV IE911}

M. E. Huckman, 1. M. Latheef, R. G. Anthony

Texas A\&M University, College Station, IX, 77843-3122

Deparment of Chemical Engineering

Kinetics, Catalysis, and Reaction Engineering Group

Scptembet 11, 1998

\section{Introduction}

Ion Exchange using the CST labeled IONSIV IEP11 is one of four technologies being cvaluated for rcmoving Cesium from the aqucous tank wastes at the Savannah River Sife. This report addresses the design of a two-column ion exchange carousel to utilize the CST for SRS waste treatment.

The report is divided into three parts and appendices. In part 1, the details of the specific design cases required by the project task list are presented. Part 2 justifies and then demonstrates the use of space velocity as the design variable for the ion exchange carousel. Part 3 reports on a modeling effort using data from experiments at ORNL, PNNL, Hanford, and Sandia. Additional data and comments are presented in the appendices of the report. 
WSRC-TR-98-00343 Rev.0

Page 39 of 69

APPENDIX B (continued)

\section{Part 1: Evaluation of the Design Cases Presented by SRS}

The two design cases presented by SRS are as follows

Case 1) With the column diameter fixed at four feet rocommond the necessary column length for a two column carousel systcm. Parallel trains of columns can be used if neccssary.

Case 2) With individual column lengths fixed at 16 fect, what column diameter is required (maximum diameter is eight feet) for a two column carousel system. Parallel trains of columns can be used if necessary.

A third column is actually present in the proposed carousel system, but SRS prefers that this column be operated strictly as a guard column. Therefore it is not considered in the design. The design specifications are that the $\mathrm{Cs}^{+}$concentration in the effluent from the first column be $90 \%$ of the feed concentration when the effluent from the second column reaches $1.3 \mathrm{ppb}$. The design cases are evaluated for the three waste compositions labeled Avg $\mathrm{HiOH}$, and HiNO, as well as for two flow rates, $15 \mathrm{gpm}$ and $25 \mathrm{gpm}$.

Method

The design oases were evaluated using the Texas A\&M column carousel model. This model simulates ion exchangc column performance in a carousel process like that proposed by SRS. The model accounts for axial dispersion, film resistance to diffusion, and intraparticle resistance to diffusion, and can accammodate both linear and non-linear isotherms. Furthermore, the model accounts for the process changes associated with column switching.

The film mass transfer coefficient is estimated using Equation 16-71 from Perry's Handbook for Chemical Engincers. The axial dispersion coefficient is estimated from the correlation proposed by Suzuki and Smith. An effective diffusivity of $0.2 \times 10^{-10} \mathrm{~m}^{2} / \mathrm{s}$ was used. In experiments performed at TCXas A\&M in a simulant similar to SRS waste the effective diffusivity of cesium was estimated as $0.3 \times 10^{-10} \mathrm{~m}^{2} / \mathrm{s}$. The smaller value used for this study yields a more conservative design.

Column experiments are currently underway at SRS to mcasure breaktirough curves using solutions representative of SRS waste. These experimental data can, and should, be used to finetune the estimate for the effective diffusivity. In general, we have observed that the effective diffusivity decreases as the sodium concentration increases. We currently believe that this effect is not due to sodium, per se, but results because sodium is driving the overall fluid properties, particularly viscosity.

The ion exchange isotherms were constructed from the information provided by Roy Jacobs in an August 20, 1998 E-mail. This E-mail contained equilibrium data generated by the Texas A\&M powder equilibrium model for nominal and bounding compositions of the wastes labeled Avg, HiOH, and HiNO. In addition there were equilibrium data for 2 waste labeled MVST-29. The model predicted solid loadings were multiplied by 0.7 to correct for the dilution of the

Q) Texas A\&M University - Deparunent of Chemical Engineering 


\section{APPENDIX B (continued)}

powder in the engineered granules. (This tochnique was requested by SRS.) This adjusted data was then fit using a Langmuir isotherm. The isotherm parametors for all the wastes are shown in Table 1.1. The design cases are only evaluated for the nominal compositions of Avg, HiOH and HiNO, although the remaining wastes are further examinod in part 2 and in appendix $D$. It is worth noting here that the nominal compositions resulted in the most conservative column design (i.e. the largest ion exchange bed volume in the carousel)

Table 1.1. Isotherm parameters for the seven waste compositions provided by Roy Jacobs. Only the nomizal compositions of Avg, HiOH, and HiNO were evaluated for the design cases. The other compositions are further examined in part 2.

\begin{tabular}{ccc}
\hline Waste & Qt (mg/g) & $\mathrm{K}\left(\mathrm{m}^{3} / \mathrm{mol}\right)$ \\
\hline Avg-nominal & 54.0 & $4.11_{-}$ \\
Avg-bounding & 54.0 & 2.63 \\
HiOH-nominal & 53.9 & 5.00 \\
HiOH- bounding & 53.9 & 3.36 \\
HiNO-nominal & 54.0 & 3.49 \\
HiNO-bounding & 53.9 & 2.22 \\
MVST-29 & 49.6 & 1.59 \\
\hline
\end{tabular}

\section{Case I Results}

For each of the three compositions, the Texas A\&M column carousel model was used to simulate a two columns in series carousel system with a column diameter of 4 feet (the two columns are identical). The lengths of the columns were increased until the design effluent concentration criterion was satisfied after the system reached steady state operation. This procedure was repeated for both flow rates. The results are summarized in Table 1.2 
APPENDIX B (continued)

Table 1.2. Summary of Case 1 design excrcise results. The column diameter is fixed at four feet. The design is for two-column carousel system with no parallcl trains. The lengths are for individual columns. The space velocities (S.V.) is based on the carousel volume.

\begin{tabular}{cccccccc}
\hline Waste & Flow Rate & $\begin{array}{l}\text { Length } \\
(1 \mathrm{col}) \text { ) }\end{array}$ & $\begin{array}{l}\text { Carous. } \\
\text { Volumc }\end{array}$ & $\mathrm{K}_{\mathrm{d}}$ & S.V. & $\begin{array}{c}\Delta \mathrm{P} / \text { column } \\
\text { (PSI }\end{array}$ & Sup. Vel. \\
\hline Avg & $15 \mathrm{gpm}$ & $16.3 \mathrm{ft}$ & $.412 \mathrm{ft}^{3}$ & 1060 & $0.29 \mathrm{~h}^{-1}$ & 5.8 & $4.9 \mathrm{~cm} / \mathrm{min}$ \\
Avg & $25 \mathrm{gpm}$ & $27.2 \mathrm{ft}$ & $686 \mathrm{ft}^{3}$ & 1060 & $0.29 \mathrm{~h}^{-1}$ & 16.5 & $8.1 \mathrm{~cm} / \mathrm{min}$ \\
HiOH & $15 \mathrm{gpm}$ & $7.41 \mathrm{ft}$ & $187 \mathrm{ft}^{3}$ & 713 & $0.65 \mathrm{~h}^{-1}$ & 2.6 & $4.9 \mathrm{~cm} / \mathrm{min}$ \\
HiOH & $25 \mathrm{gpm}$ & $12.3 \mathrm{ft}$ & $312 \mathrm{ft}^{3}$ & 713 & $0.65 \mathrm{~h}^{-2}$ & 7.4 & $8.1 \mathrm{~cm} / \mathrm{min}$ \\
HiNO & $15 \mathrm{gpm}$ & $18.6 \mathrm{n}$ & $468 \mathrm{ft}^{3}$ & 953 & $0.26 \mathrm{~h}^{-1}$ & 6.6 & $4.9 \mathrm{~cm} / \mathrm{min}$ \\
HiNO & $25 \mathrm{gpm}$ & $31.0 \mathrm{ft}$ & $780 \mathrm{ft}^{3}$ & 953 & $0.26 \mathrm{~h}^{-1}$ & 18.8 & $8.1 \mathrm{~cm} / \mathrm{min}$ \\
\hline
\end{tabular}

Figure 1.1 shows an example output from the Tcxas A\&M column carousel model. The output is from the worst case of the three compositions considered in this section, HiNO. In a twocolumn carousel system, when the $\mathrm{Cs}^{+}$concentration in the effluent from the second column reaches the maximum allowable value of $1.3 \mathrm{ppb}$, a column switch occurs. After a column switch, the second column becomes the first, or lead column and a fresh column is introduced as the second column. Figure 1.1 illustrates how the effluent concentration from the lead column of the system behaves as the carousel progresses through a series of switches. During the initial cycle the lead column bocomes highly loaded. However, the icad column loading decreases with successive cycles and eventually reaches a steady state. There are two reasons for this behavior. First, as the concentration front moves through the ion exchange bed it will continue to spread for some time. Second, each column switch introduces a jump in the feed concentration to the new first column. In other words, before a column switch, the second column inlet is at $90 \%$, after the switch the second column becomes the lead column and the inlct concentration jumps to $100 \%$. 
APPENDIX B (continued)

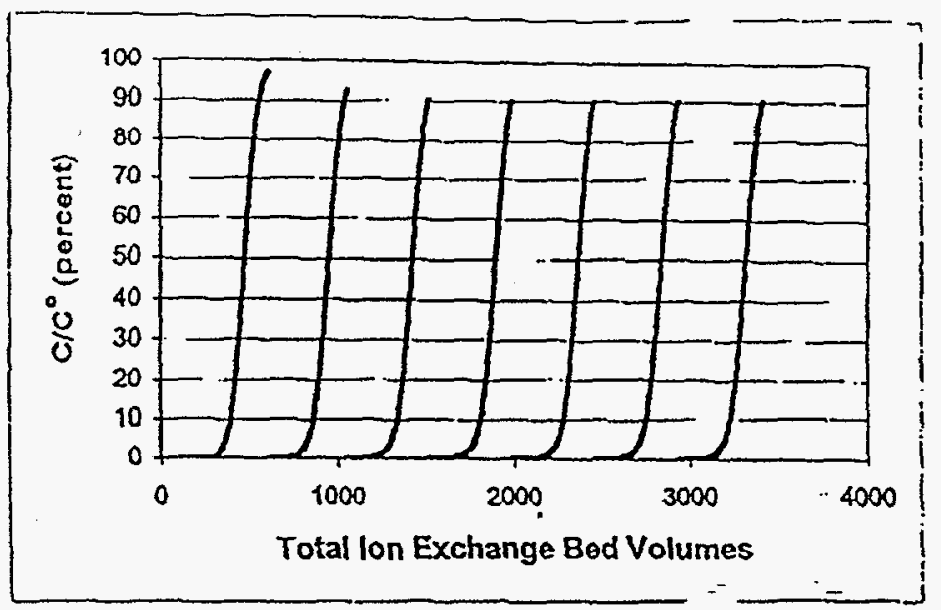

Figure 1.1. Example illustration of lead column effluent behavior as the carousel system progresses through a series of column switches. This example is the design simulation for HinO waste, at $25 \mathrm{gpm}$, with a column diamcter of four feet.

In this analysis, only one train of columns is considered. While the number of trains issue is addressed here, some of the conclusions from part 2 are needed to fully appreciate the reasoning behind this response. With that in mind, additional trains can be added to the carousel and the carousel performance will not change, provided that the total volume of the ion exchange carousel (sum of the volumes in all the columns) remains constant and the flow is split evenly between the trains. In other words, as long as the space velocity is held constant, the performance of the carousel does not change.

The pressure drop per column was caiculated from the figure that was presented on page 32 of ORNL report TM-13503. The pressure drop was found by sublracting the data for the empty column from that for the packed column with the simulant as the working fluid. Thus the numbers in the pressure drop column only represent the pressure drop due to the packing.

The length of the mass transfer zone can be easily found as follows. Once the carousel reaches steady state; the front of the mass transfer zone is located at the outlet of the last column and the back of the mass transfer zone is located at the outlet of the first oolumn. This method of identifying the length of the mass transfer zone is valid regardless of the number of columns in the carousel, provided that the carousel is meeting the design specifioations. Note that the design specifications effoctively define the mass transfer zone. Figure 1.2 illustrates this point by plotting the carousel concentration profile as a function of dimensionless carouscl length. In a two column cacousel, the first column outlet is at 0.5 and the figure shows that the concentration at that point is $90 \%$. 


\section{APPENDIX B (continued)}

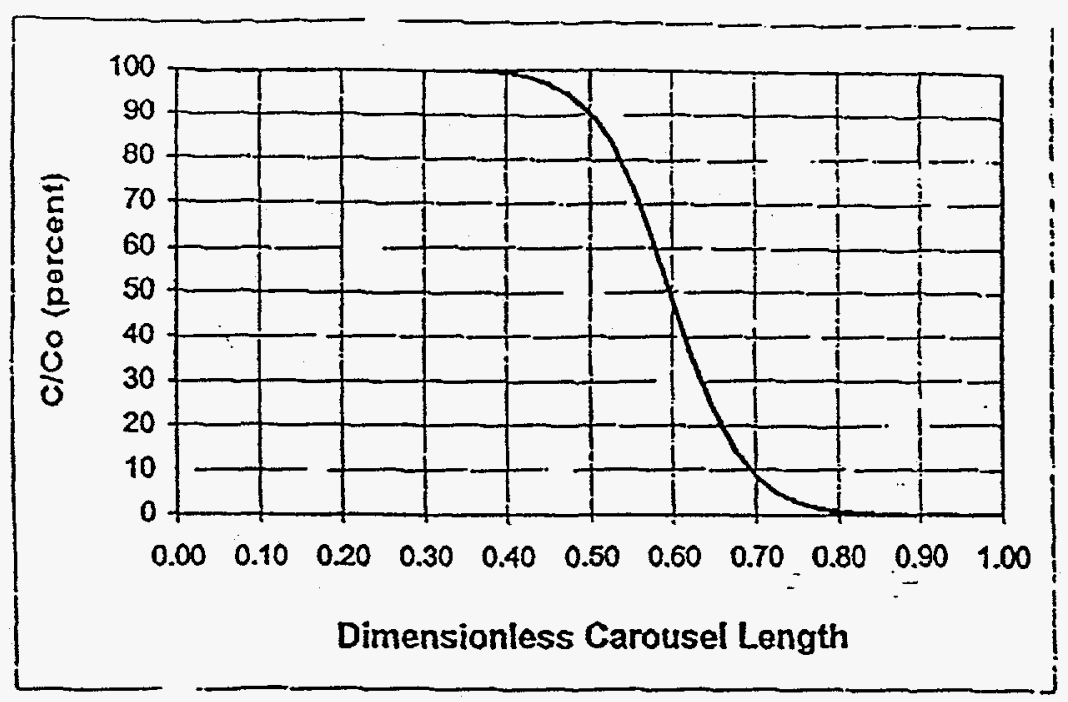

Figure 1.2. The carousel concentration profile plotted as a function of dimensionless carousel length. The first column outlet is located at 0.5 and the concentration here is $90 \%$. For this twocolumn case, the mass transfer zone extends from 0.5 to 1.0. Taken from the design simulation for HinO waste, with a flow rate of $25 \mathrm{gpm}$, and a column diameter of four feet.

\section{Case 2 Results.}

A procedure similar to that usod for design case 1 was used to evaluate design case 2. However, for this design case, the length of the individual columns was held constant at 16 feet and the diameter was increased until the effluent concentration criteria was satisfied at steady state. The results are shown in Table 1.3. The combinations of composition and flow rate are the same as in case 1. The pressure drop per column was calculated in the same manner as was done for case 1.

It is instructive to notice that for a given flow rate, the volumes required for case 1 and case 2 are identical. Also, for any given waste composition, the space velocity is identical regardless of the flow rate, or the diameter of the column. This observation hints at two conclusions. The first is that the performance of the carousel is determined by space velocity and is not affected by the superficial velocity. The second is less obvious, but is as follows. When the carousel concentration profiles are plotted versus volume, instead of versus actual length, the profiles are identical regardless of the column diameter. This is made morc clear by choosing a composition and flow rate and then comparing the results for case 1 and case 2 . The front and back of the mass transfer zone are located at the first and second column outlets which have different lengths for the two design cases, but represent identical volumes. Thus, if these conclusions prove accurate, Figures 1.1 and 1.2 apply oqually well to both cases.

Q Texas A\&M University - Department of Chemical Engineering 
Table 1.3. Summary of Case 2 design exercise results. The column lengths are fixed at sixteen feet. The design is for two-column carousel system with no parallel trains. The space velocities are based on the carousel volume.

\begin{tabular}{lccccccc}
\hline Waste & Flow Rate & Dirm. & $\begin{array}{c}\text { Carous. } \\
\text { Volume }\end{array}$ & $\mathrm{K}_{\mathrm{s}}$ & $\mathrm{S.V}$. & $\begin{array}{c}\Delta \mathrm{P} / \text { column } \\
\text { (PSI }\end{array}$ & Sup. Vel \\
\hline Avg & $15 \mathrm{gpm}$ & $4.05 \mathrm{ft}$ & $412 \mathrm{f}^{3}$ & 1060 & $0.29 \mathrm{~h}^{-1}$ & 5.5 & $4.8 \mathrm{~cm} / \mathrm{min}$ \\
Avg & $25 \mathrm{gpm}$ & $5.22 \mathrm{ft}$ & $686 \mathrm{ft}^{3}$ & 1060 & $0.29 \mathrm{~h}^{-1}$ & 5.5 & $4.8 \mathrm{~cm} / \mathrm{min}$ \\
FHOH & $15 \mathrm{gpm}$ & $2.73 \mathrm{ft}$ & $187 \mathrm{ft}^{3}$ & 713 & $0.65 \mathrm{~h}^{-1}$ & 12.7 & $10.5 \mathrm{~cm} / \mathrm{min}$ \\
HiOH & $25 \mathrm{gpm}$ & $3.52 \mathrm{ft}$ & $312 \mathrm{ft}^{3}$ & 713 & $0.65 \mathrm{~h}^{-1}$ & 12.7 & $10.5 \mathrm{~cm} / \mathrm{min}$ \\
HiNO & $15 \mathrm{gpm}$ & $4.32 \mathrm{ft}$ & $468 \mathrm{ft}^{3}$ & 953 & $0.26 \mathrm{~h}^{-1}$ & 4.8 & $4.2 \mathrm{~cm} / \mathrm{min}$ \\
HiNO & $25 \mathrm{gpm}$ & $5.57 \mathrm{ft}$ & $780 \mathrm{ft}^{3}$ & 953 & $0.26 \mathrm{~h}^{-1}$ & 4.8 & $4.2 \mathrm{~cm} / \mathrm{min}$ \\
\hline
\end{tabular}

Case 2, as originally posed by SRS included the question "how many columns are necessary?". The design criteria can be met using a carousel with any number of columns greater than one. However, the required carousel volume will change depending on the number of columns in the carousel. This question is further addressed in part 2.

The maximum allowable column diametcr was 8 feet. The largest required diameter was 5.6 feet. Thus, only one train of columns was considered Again, additional trains can be added if desired as mentioned under case 1 . 
WSRC-TR-98-00343 Rev.0

Page 45 of 69

APPENDIX B (continued)

\section{Part 2: Some General Observation Regarding the lon Exchange Column Design}

This section communicates some additional observations regarding the design of an ion exchange column carousol systcm for treating SRS waste. In particular, this section shows that the superficial velocity does not affect the spread of the column concentration profile in the range of operating conditions being considered by SRS, provided that the space velocity is held constant. Thus space velocity, or residence time, is the natural design variable. Also, by using space velocity, a large amount of design information is displayed in a simple format and comments are included regarding possible design options/problems.

To determine the effect of the superficial velocity on the column breakthrough curve, 10 cases were evaluated. The cases are for a constant feed rate of $25 \mathrm{gpm}$ and a constant column volume of $276 \mathrm{ft}^{3}$. Ten different column diameters were usod ranging from one to cight feet. The cases are summarized in Table 2.1. Notice that the space velocity is held constant while the superficial velocity varies by a factor of 64 . The predicted breaktbrough curves were for a single ion exchange column, and the isotherm was assumed to be linear with a distribution coefficient of $1570 \mathrm{mV} / \mathrm{g}$.

When considering changes in superticial velocity, the film mass transfer coeflicient and the axial dispersion coefficiont are the two parameters affected. The effective diffusivity and the isotherm remain unchanged. Thus, though it is the superficial velocity that is being variod, what is actually being evaluated is the effoct of changes in the film resistance to mass transfer and the axial dispersion on the column performance. 
APPENDIX B (continued)

Table 2.1. Ten cases used to evaluate the cffect of superficial velocity on the column breakthrough curves and concentration profiles. The space velocity is hcld constant while the superficial velocity is varied by changing the colvmn diameter.

\begin{tabular}{lccccc}
\hline & Diameter (ft) & Length $(\mathrm{ft})$ & S.V. $\left(\mathrm{h}^{-1}\right)$ & $\begin{array}{c}\text { Superficial } \\
\text { Vclocity } \\
(\mathrm{cm} / \mathrm{min})\end{array}$ & Volume $\left(\mathrm{f}^{3}\right)$ \\
\hline Case 1 & 8 & 5.5 & 0.725 & 2.03 & 276 \\
Case 2 & 6 & 9.8 & 0.725 & 3.61 & 276 \\
Case 3 & 5 & 14.1 & 0.725 & 5.19 & 276 \\
Case 4 & 4 & 22 & 0.725 & 8.11 & 276 \\
Case 5 & 3.5 & 28.7 & 0.725 & 10.6 & 276 \\
Case 6 & 3.0 & 39.1 & 0.725 & 14.4 & -276 \\
Case 7 & 2.5 & 56.3 & 0.725 & 20.8 & 276 \\
Case 8 & 2.0 & 88 & 0.725 & 32.4 & 276 \\
Case 9 & 1.5 & 156.4 & 0.725 & 57.7 & 276 \\
Case 10 & 1.0 & 352 & 0.725 & 130 & 276 \\
\hline
\end{tabular}

Figure 2.1 shows that the model predicted breakthrough curves are identical. Thus, over a larye range of superficial velocitics, the breakthrough curve is determined only by the space velocity. The deeper conclusion is that over this range of supericial velocities, the corresponding changes in the film resistance to diffusion and the axial dispersion do not change the shape of the column breakthrough curve. It is important to point out that when column breakthrough curve does not change, this necessarily implies that the column concentration profile does not change, provided it is plotted versus volume and not actual length. 


\section{APPENDIX B (continued)}

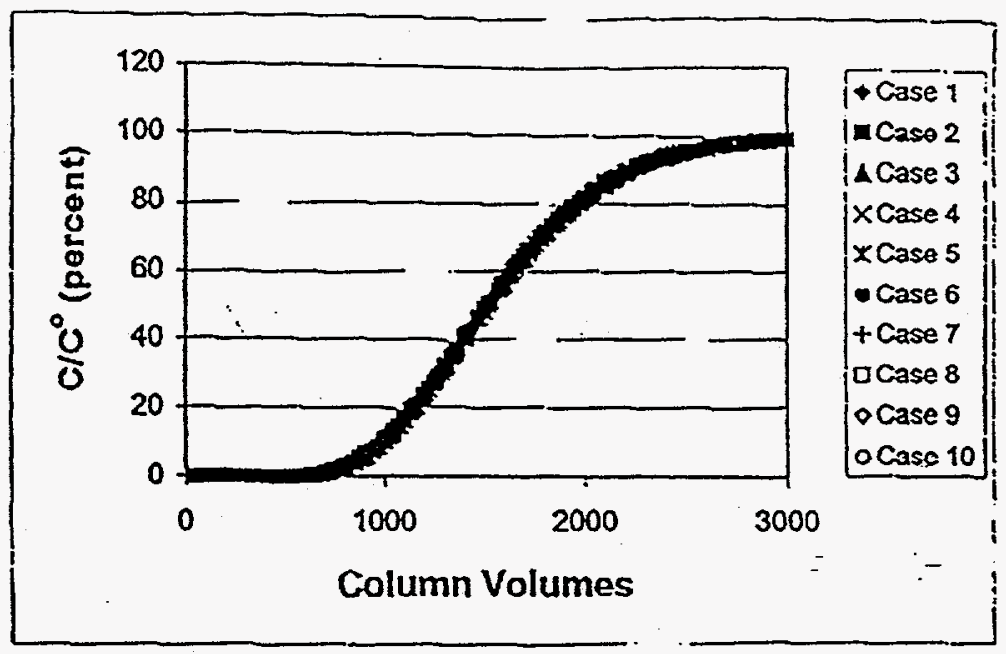

Figure 2.1. One column breakthrough curves for the ten cases described in Table 2.1. The breakthrough curves are indistinguishable indicating that superficial velocity does not affect column performance, provided that space velocity is held constant.

The Tcxas A\&EM colunn carousel model was used to construct design curves with space velocity as the design variable. These curves are shown in Figure 2.2. The curves plot the space velocity required to meet the column effluent specifications at steady state versus the number of columns in the carousel for six of the waste compositions (MVST-29 is addressed in appendix D). The space velocity is based on the total volume of the carousel. Figure 2.3 contains similar information, but the space velocity is used to calculate a total carousel volume based on a flow rate of $25 \mathrm{gmm}$. Figure 2.4 plots the interval between column switches.

Figures 2.2 and 2.4 remain unchanged if the flow rate changes. Figure 2.3, however, can be casily recalculated by converting the space velocities to a total carousel volume based on the new flow rate, for example $15 \mathrm{gpm}$.

From either Figure 2.2 or 2.3 one can easily visualize the difference in the carousel performance for different waste compositions. The waste composition labeled HiNO requires the smallest space velocity, hence, the largest carousel volume for a given flow rate. The other extreme is the waste labciod HIiOH-b (bounding) which allows for the largest space velocity, hence, the smallest carousel volume for a given flow rale. These figures indicate the importance of clearly defining the range of possible column feed compositions. They also show that the bounding compositions do not yield the most conservative design cases.

Because the bounding compositions do not identify the worst design cases, we strongly recommend that an effort be undertaken to identify worst case compositions. While some additional work would be required before we could provide firm guidance for identifying worst 
WSRC-TR-98-00343 Rev.0

Page 48 of 69

\section{APPENDIX B (continued)}

case compositions, we have found that, in general, the wastes with the highest $K_{d}$ and the lowest $\mathrm{Cs}^{+}$concentrations require the smallest space velocities, hence are the worst design cases.

Once the worst case compositions are identified, the carousel doesn't have to be designed to treat them. Instead, a well-managed blending program upstream of the carousel can keep the carousel feed composition inside appropriate limits. In this manner, a smallet carouscl can be used to treat a variety of waste compositions. However, it remains necessary to better understand how waste composition affects carousel requirements to properly manage upstream bleading.

Figures 2.2 and 2.3 also illustrate how the total carousel volume required to treat a given waste decreases as the number of working columns in the system increases. The decrease is substantial moving from two columns to three columns or even from three columns to four columns. For example, the total carousel volume required to treat HinNO decreases by almosit $30 \%$ when the number of working columns increases from two to three. The decrease becomes more modest as the number of columns increases. The change interval, shown in Figure 2.4, can become an issue as the number of columns increases because it is reduced to matter of days for several of the compositions. However, we recommend that the number of columns in the carousel be considered a design variable.

Figure 2.4 can be used to find the rate of CST consumption by dividing the volume of an individual column by the switch interval. It is important to note that as the distribution coefficient of a given waste decreases, the amount of CST required to treat that waste increases. Thus, for a given flow rare of waste, a small distribution coefficient implies a large rate of CST usage. Howcver, a large rate of CST usage does not imply that a large ion exchange column is required. In fact, for the waste compositions considered here, those resulting in the lowest distribution coefficients generally require the smallest column sizes.

The relationship between the distribution coefficient, the rate of CST usage, and the roquired size of ion exchange bed can be summarized as follows. The amount of CST required to treat a given volume of waste is determined solely by the distribution coefficient and the percent saturation of the lead column (which is a design specification). However, the size of the ion exchange column nooded to perform that operation is a complicated function of several variables such as the feod concentration, the distribution coefficient, and the shape of the isotherm. 


\section{APPENDIX B (continued)}

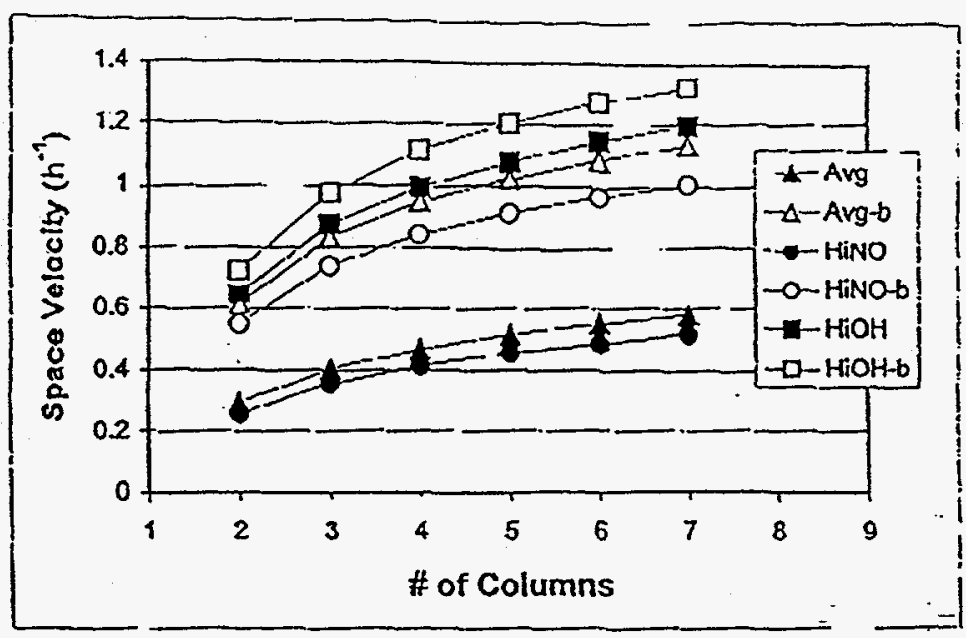

Figure 2.2. Required space velocity (based on the total carousel volume) versus the number of columns in the system for six waste compositions. The worst design case composition is HiNO which has the lowest space velocity.

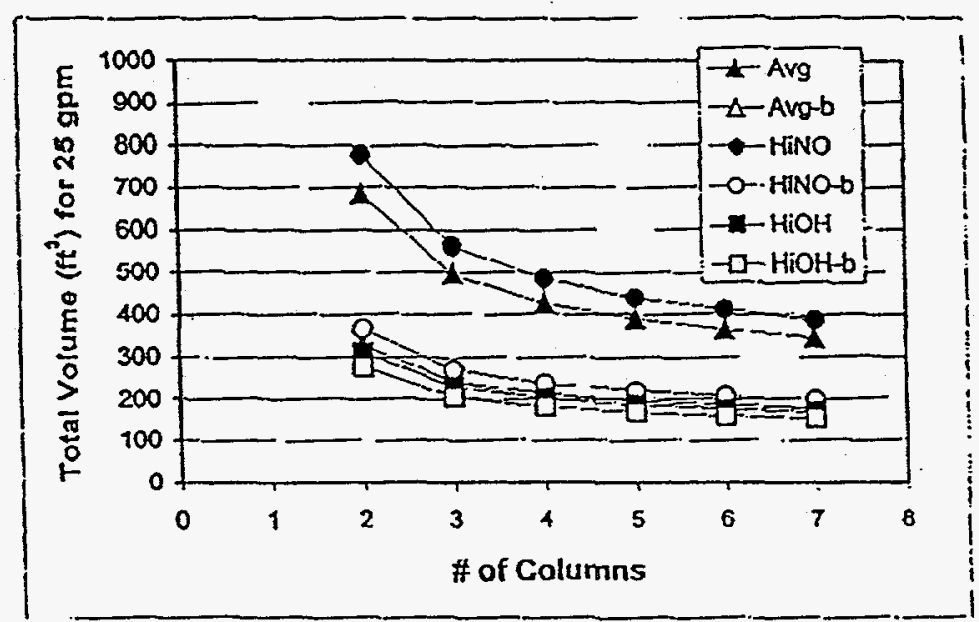

Figure 2.3. Required tocal carousel volume (based on a flow rate of $25 \mathrm{gpm}$ and calculatcd from Figure 2.2) versus the number of columns in the system for six waste compositions. The waste labeled HiNO, which required the smallest space velocity, here requires the largcst total bed volume. 


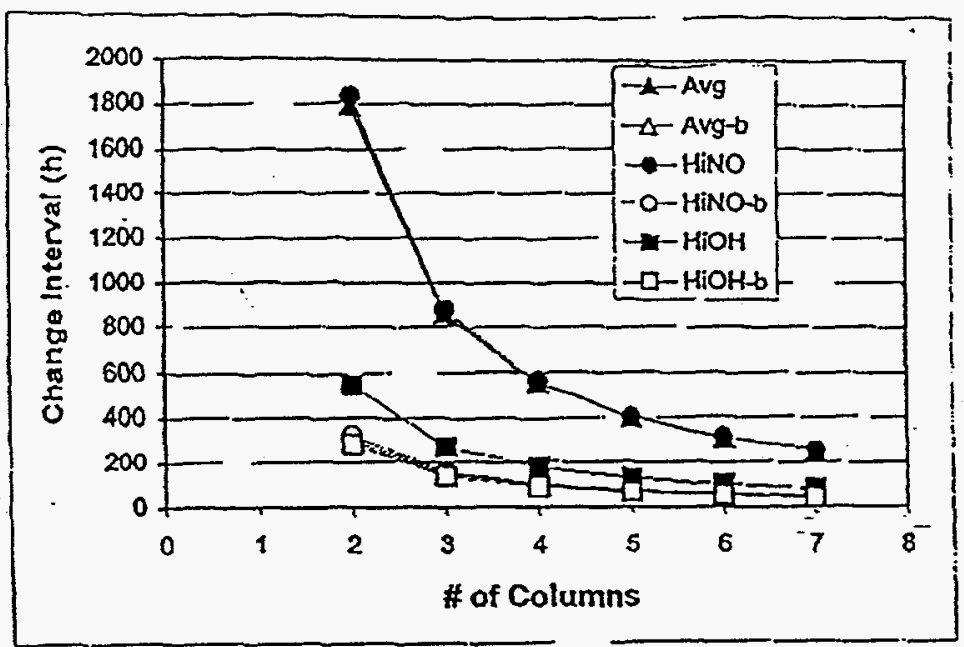

Figare 2.4. Interval between column switches versus the number of columns in the system for six wastc compositions. The rate of CST usage is calculated by dividing an individual column volume by the switch interval. 
WSRC-TR-98-00343 Rev.0

Page 51 of 69

\section{APPENDIX B (continued)}

\section{Part 3: Modeling Previous Column Experiments}

The Texas A\&M ion exchange column model was used to simulate four experiments provided by Scot Beck and Roy Jacobs. Because the Texas AdM model is very different from the model developed by SRS, it is not possible to directly compare parameter values between models. Thus, the primary objective of this exercise was to examine the consistency of the parameters. If the modeling parameters are found to be consistent, this implies that the model is a fairly accurate representation of the process.

The maximum $\mathrm{Cs}^{+}$concentration in those experiments was less than $10 \mathrm{ppm}$ and at these low concentrations, the ion exchange isotherm is approximately linear. Thus, the experiments were modeled using a linear isotherm. The distribution coefficient (the slope of the isotherm) and the effective diffusivity were varied by trial and error to fit the experimental data. The best fit distribution coefficient was then compared to the distribution coefficient predicted by the Texas A\&M powder equilibrium model to determine a dilution factor for predicting equilibrium on the engineered granules.

The results of this exercise are summarizod in Table 3.1. The dilution factor is very consistent and varies between 0.61 and 0.66 . Three of the experiments, MVST W-29, MVST W-27, and Sandia DSSFS, wcre modeled using an effective diffusivity of $0.8 \times 10^{-10} \mathrm{~m}^{2} / \mathrm{s}$. The fourth experiment, $\Lambda W-101$, was modeled using an effoctive diffusivily of $2.0 \times 10^{-10} \mathrm{~m}^{2} / \mathrm{s}$. Figures 3.1 through 3.4 plot the available experimental data versus the best-fit model simulation for the four. experiments.

Two important notes should be made regarding this exercise. First, the average particle diameter was unknown for all of these experiments. Based on IONSIV IE-911 particle size distribution information from Texas A\&M laboratories, the average particle diameter was estimated to be $375 \mathrm{\mu m}$. However, the actual size of the particles in the column can be afrected by a variety of factors, including particle pretreatment, or the technique used to remove fines. Secondly, only three dats points were available for cach experiment, the $1 \%, 10 \%$ and $50 \%$ breakthrough points. In general, we have observed that when one focuses on fitting the front portion of a column breakthrough curve, one estimates a slightly larger effective diffusivity than if one fits the model to an entire breakthrongh curve. Thus it is difficult to comment with certainty on the estimated effective diffusivities, except to note thiat overall the values appear consistent.

While it is not possible to directly compare parameter values with those previously estimated by Beck \& Jacobs, the differences between the models can be highlighted. The Beck \& Jacobs model assumod that film resistance to diffusion controlled the rate of mass transfer. Our results indicale that film resistance is relatively unimportant, and that the rate of mass transfer is actually controlled by intraparticle resistance to diffusion, which is quantified by the effective diffusivity. Also, Beck \& Jacobs varied the bed porosity to fit the experimental data. Data from our laboratory indicates that the bed porosity is very nearly constant at 0.5 .

(c) Texas A\&M University - Department of Cheraical Engincering 


\section{APPENDIX B (continued)}

Table 3.1. Summary of best fit parameters for four ion exchange column experiments using the Texas A\&AM ion exchange columu model. Because the $\mathrm{Cs}^{+}$concentrations for these experiments were all less than 10ppm, the experiments were modeled using a linear isotherm.

\begin{tabular}{ccccc}
\hline Experiment & Best fit K & Predicted Kd & Dilution Factor & $D_{\text {etrective }}$ \\
\hline Sandia DSSFS & 575 & 910 & 0.63 & $0.8 \times 10^{-10}$ \\
MVST W-29 & 575 & 950 & 0.61 & $0.8 \times 10^{-10}$ \\
MVST W-27 & 375 & 600 & 0.63 & $0.8 \times 10^{-10}$ \\
Hanford AW-101 & 775 & 1173 & 0.66 & $2.0 \times 10^{-10}$ \\
\hline
\end{tabular}

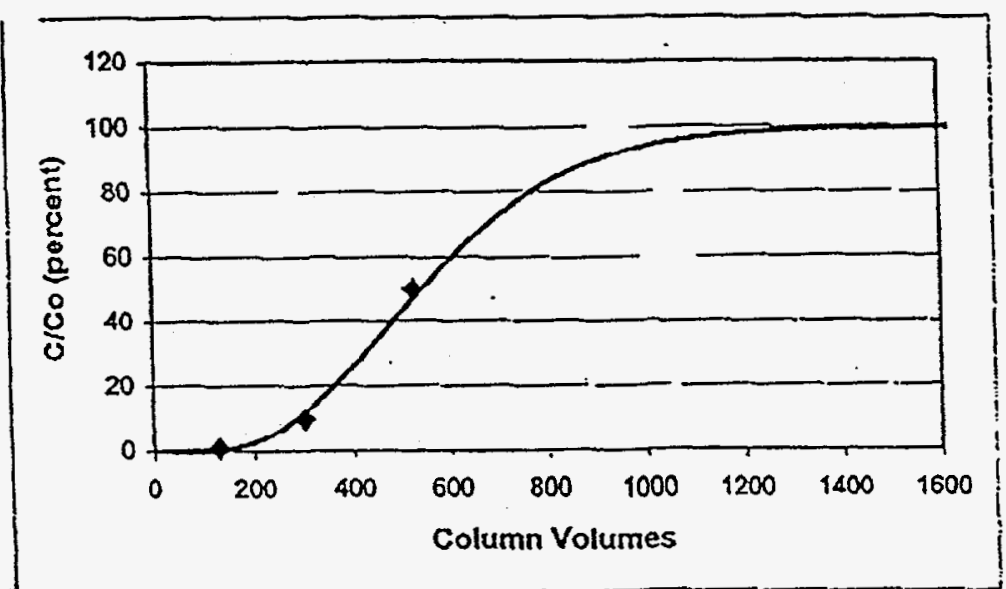

Figure 3.1. Available experimental data and Texas A\&M ion exchange column model simulation for the Sandia DSSF5 experiment. The best fit effective diffusivity and distribution coefficient are shown in Table 3.1 . 


\section{APPENDIX B (continued)}

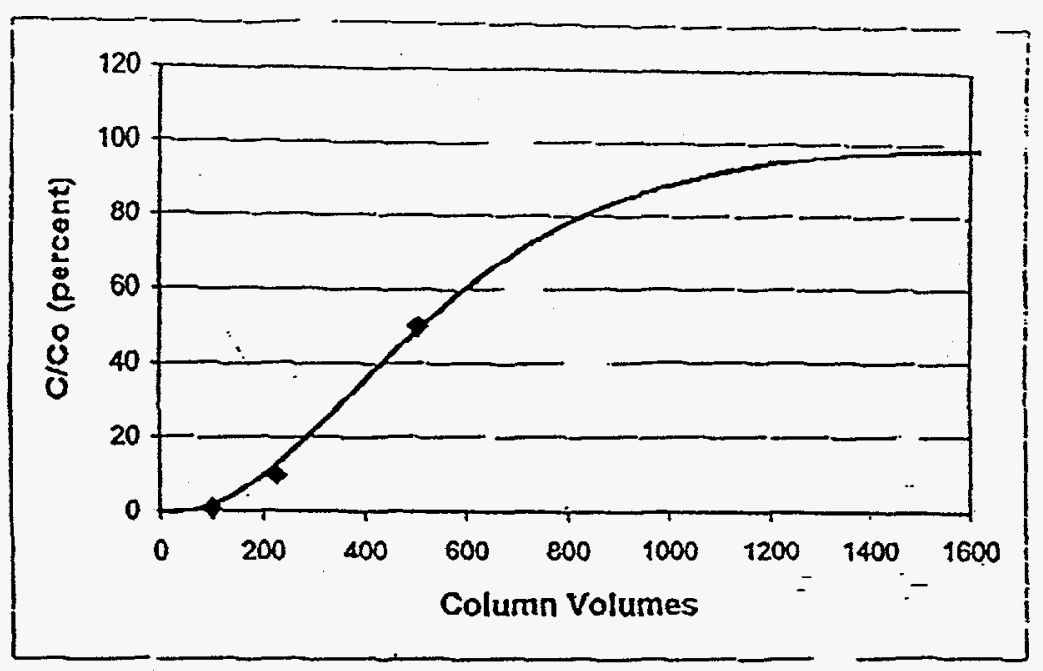

Figure 3.2. Available experimental data and Texas A\&M ion cxchange column model simulation for the MVST W-29 experiment. The best fit effective diffusivity and distribution coefficient are shown in Table 3.1.

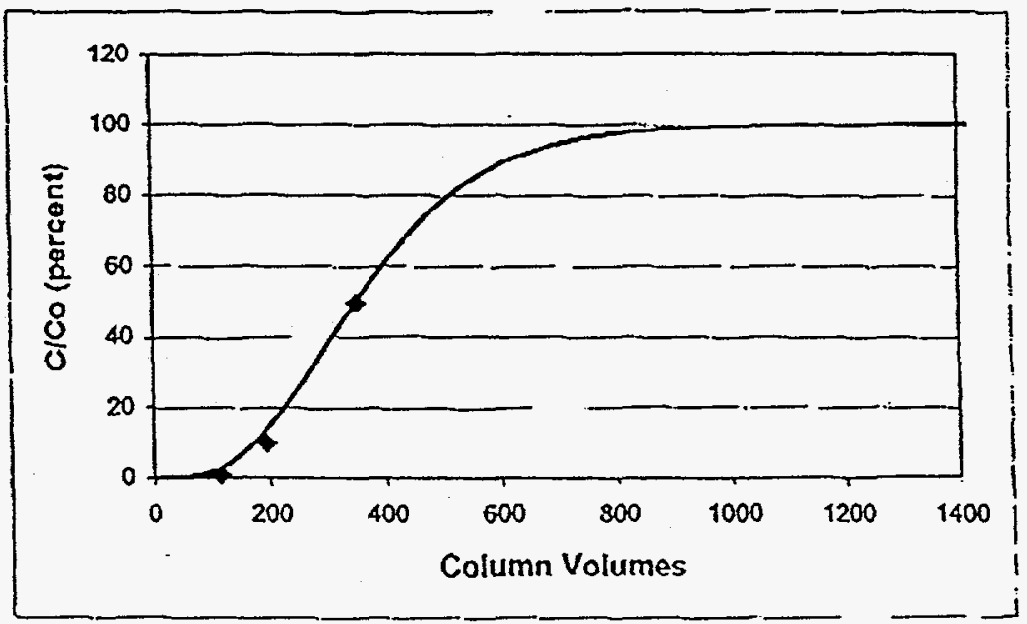

Figure 3.3. Available experimental data and Texas A\&M ion exchange column model simulation for the MVST W-27 experiment. The best fit effective diffusivity and distribution coefficient are shown in Table 3.l. 
WSRC-TR-98-00343 Rev.0

Page 54 of 69

APPENDIX B (continued)

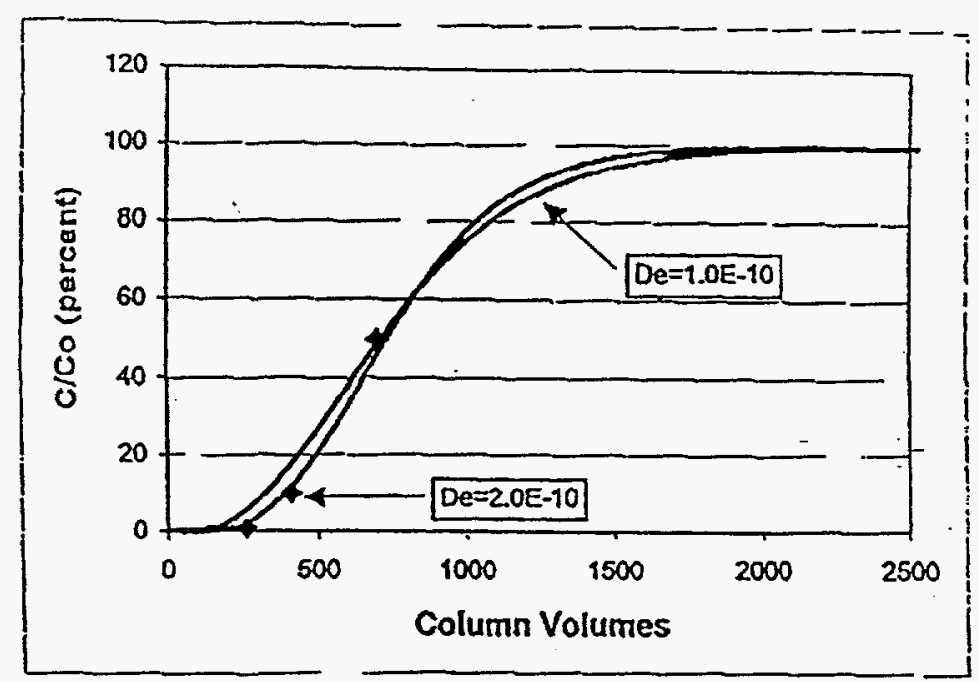

Figure 3.4. Available experimental data and Texas A\&M ion exchange column model simulation for the Hanford AW-101 experiment. The best fit effective diffusivity and distribution coeflicient are shown in Table 3.1.

$\theta$ Texas A\&M Úniversity - Department of Chemical Eagineering 


\section{APPENDIX B (continued)}

\section{A. Analysis of Solid Loading in the Ion Exchange Column for UOP IONSIVTM IE-911}

Ion exchange column experiments have been conducted at Texas A\&M to investigate the $\mathrm{Cs}$ solid loading profile along the length of the column. The data presented here are for two experiments conducted in standard simulant (5.1 M NaNO $3,0.6 \mathrm{MNaOH}$ ) for the UOP IONSIV IE-911-94 granules. The first experiment was stopped at $200 \mathrm{CVs}$, just before breakthrough, and the solid was collected and analyzed for Cs. It should be noted that although Cs may be present in the effluent at $200 \mathrm{CVs}$ the limits of alomic absorption do not allow us to measure concentrations below $1 \mathrm{ppm} C s$ accurately. The second run was continued to a $\mathrm{C} / \mathrm{C}_{t}=0.88$ at $1130 \mathrm{CVs}$ as shown in Figure A.l. Again, the solid was collected and analyzed for Cs. The solid profiles are compared in Figure A.2.

The column is completely saturated at approximately $37 \mathrm{mg}$ Cs/g CST as indicated from the front of the column loading profile shown in Figure A.2. The percent saturation can be determined from the areas under each loading profile.

For the $200 \mathrm{CV}$ solid loading profile the area under the curve suggests that $42 \%$ of the solid was saturated just before breakthrough. For the $1130 \mathrm{CV}$ profile, the area under the curve was $87 \%$ of the total area indicating $87 \%$ of the solid was saturated with $\mathrm{Cs}$. Thus, at $\mathrm{C} / \mathrm{C}_{\mathrm{f}}=0.88$ the solid is $87 \%$ saturated with $C$ s. These data should not suggest that when the effluent concentration reaches somc $X \%$ then the solid is $X \%$ saturated and this point is clear when noting the saturation level just before $\mathrm{Cs}$ breakthrough (i.e., at $200 \mathrm{CV}$ s with $\mathrm{ClCl}=0$ the percent saturation was $42 \%$ ).

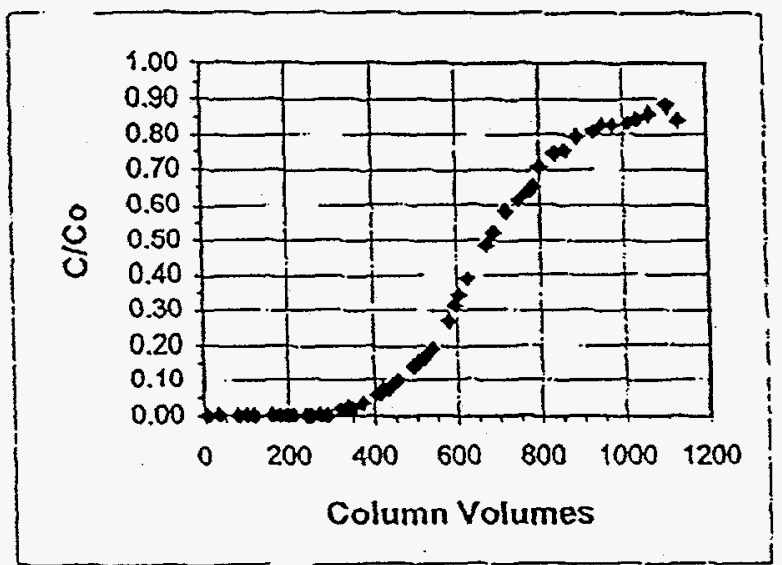

Figure A.1. Cs breakthrough profilc for UOP DE-911-94 granules (400 micron diameter) in standard simulant at $3.6 \mathrm{CV} / \mathrm{h}(4 \mathrm{~cm} / \mathrm{min})$ with $\mathrm{C}_{\mathrm{feed}}=50 \mathrm{ppm} \mathrm{Cs}$. Column dimensions were 1.1 $\mathrm{cm}$ diameter and $31.75 \mathrm{~cm}$ length for a bod volume of $30 \mathrm{~cm}^{3}$. The bed porosity was 0.5 . 


\section{APPENDIX B (continued)}

\section{A.2}

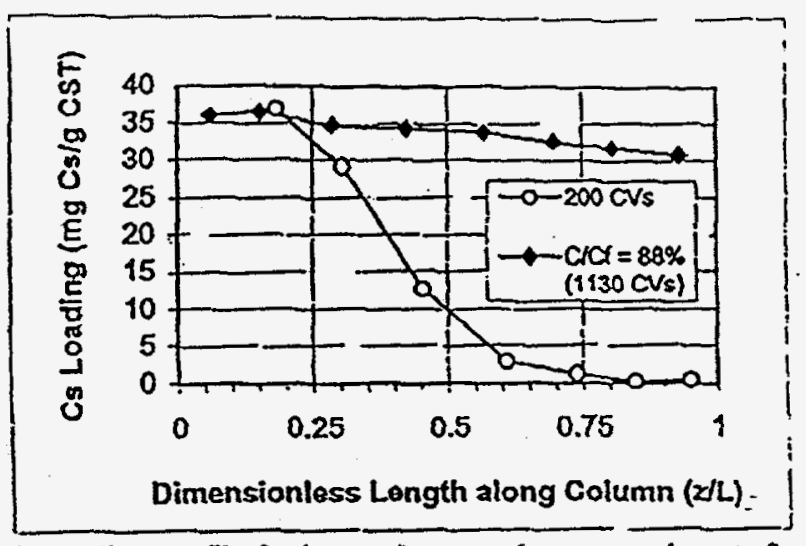

Figure A.2. Cs solid loading profile for ion exchmge column experiments for UOP IE,91 1-94 granules in standard simulant with $\mathrm{C}_{\text {tood }}=50 \mathrm{ppm}$ Cs. The first experiment was stopped at 200 $\mathrm{CVs}$ and the second run was continued until $\mathrm{C} / \mathrm{C}_{f}=0.88$. 


\section{APPENDIX B (continued)}

\section{B. Analysis of Anion Composition on Cs Distribution Coefficient}

The effect of the anion composition was examined by studying the relation between anion composition and $\mathrm{Cs}$ distribution coefficient for a standard simulant $(5.1 \mathrm{MNaNO}, 0.6 \mathrm{M}$ $\mathrm{NaOH}$ ) solucion. For this study, the $\mathrm{NO}_{3}{ }^{-}$and $\mathrm{NO}_{2}^{-}$compositions were adjusted by adding $\mathrm{NaNO}_{2}$ to the standard simulani while adjusting the $\mathrm{NaNO}_{3}$ to maintain a constant ionic strength and $\mathrm{Na}^{+}$concentration of $5.7 \mathrm{M}$ for the solution. The Texas A\&M powder equilibrium model was used to generate Cs Kd's for the various simulants listed in Table B.l.

Table B.1. Waste oompositions used to determine anion effect on Cs Ko.

\begin{tabular}{|c|c|c|c|c|}
\hline Component & Simulant $A$ & Simulant B & Simulant C & Simulant D \\
\hline $\mathrm{NaNO}_{3}$ & $5.1 M$ & $3.4 M$ & $1.7 M$ & - \\
\hline $\mathrm{NaNO}_{2}$ & - & $1.7 M$ & $3.4 M$ & $5.1 M$ \\
\hline $\mathrm{NaOH}^{2}$ & $0.6 M$ & $0.6 M$ & $0.6 M$ & $0.6 M$ \\
\hline $\mathrm{CsNO}_{3}$ & $7.0 \mathrm{E}-5 M$ & $7.0 \mathrm{E}-5 M$ & $7.0 \mathrm{E}-5 \mathrm{M}$ & $7.0 \mathrm{E}-5 M$ \\
\hline
\end{tabular}

Table B.2 shows the model predicted Cs distribution coefficients for the simulents listed in Table $\mathrm{B} .1$ along with the calculated $\mathrm{Cs}$ activity coefficients. These data indicate that as $\mathrm{NO}_{3}{ }^{-}$is replaced with $\mathrm{NO}_{2}^{-}$the $\mathrm{Cs} \mathrm{K}_{d}$ and activity coefficient increases. The activity coefficients are calculated from Bromley's model with parameters of -0.0174 for $\mathrm{NaNO}_{3}$ and 0.015 for $\mathrm{NaNO}_{2}$. Figure B.1 shows the results from Table B. 2 in graphical form.

Table B.2. Cs Ko and Activity Coefficients for Various Simulants

\begin{tabular}{|c|c|c|}
\hline Simulant & Cs $\mathbf{K}_{d}(\mathrm{~mL} / \mathrm{g})$ & $\lambda_{\mathrm{c}}$ \\
\hline $\mathrm{A}$ & 908 & 0.333 \\
\hline $\mathrm{B}$ & 1326 & 0.425 \\
\hline $\mathrm{C}$ & 1856 & 0.543 \\
\hline $\mathrm{D}$ & 2462 & 0.694 \\
\hline
\end{tabular}

(c) Texas A\&M Uniycrsity-Department of Chemical Engineeriag. 


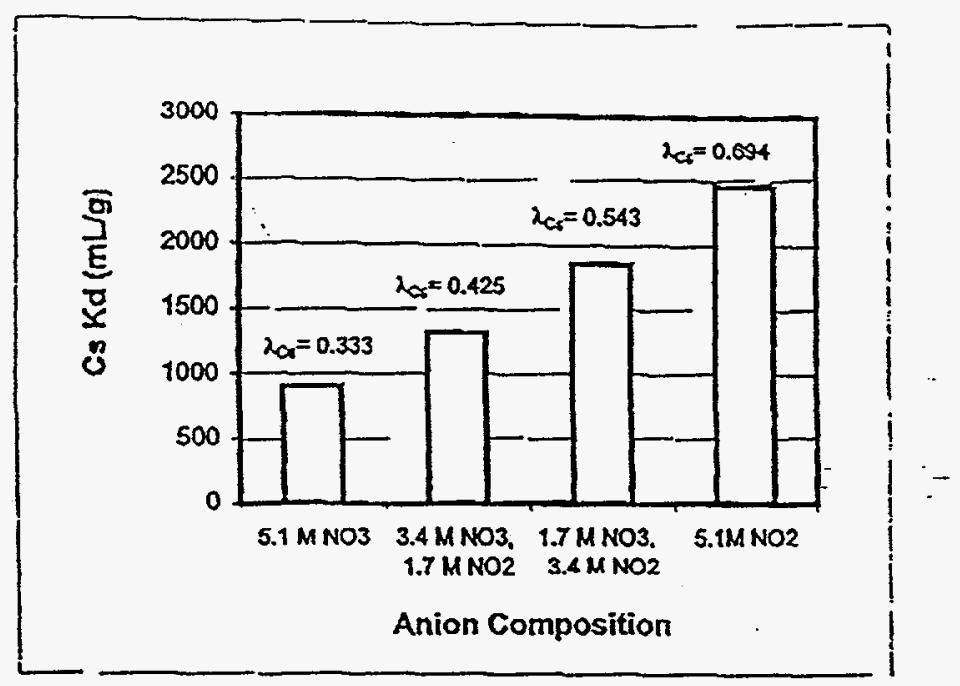

Figure B.1. The effect of $\mathrm{NO}_{2}^{-}$and $\mathrm{NO}_{3}^{-}$anions on the $\mathrm{Cs}$ distribution coefficient with the total ionic strength held constant. Also shown are the $\mathrm{Cs}_{\text {s }}$ activity coefficients for each simulant. 


\section{APPENDIX B (continued)}

\section{Analysis of Compotitive Exchange on Cs Breakthrough Profiles for UOP IONSIVMM IE-911 in SRS Waste.}

A primary concern in the treatment of the complex DOE radwastes is the competitive exchange between Cs and other components in the waste stream. The SRS wastes presented (i.e., Avg, HiOH, and HiNO) contain $\mathrm{K}^{+}$, which competes with $\mathrm{Cs}^{+}$for ion exchange sites on the IE-91I solid. Previous equilibrium experiments have shown that the equilibrium capacity of IE-911 for Cs decreases in the presence of $0.5 \mathrm{MKNO}_{3}$ for the standard simulant (5.1 $\mathrm{M} \mathrm{NaNO}_{3}$ and $0.6 \mathrm{M}$ $\mathrm{NaOH}$.

Ion exchange column experiments were conducted in both standard and standard with $0.5 \mathrm{M}$ $\mathrm{KNO}_{3}$ simulants to compare the effoct of $\mathrm{X}$ on $\mathrm{Cs}$ breakthrough. The feed concentration was 50 $\mathrm{ppm} \mathrm{Cs}$ and flow rates were 3.6-3.8 CV/h. The decrease in equilibrium capacity translatod into an earlier brcalthrough as shown in Figure C.l. However, when studying the $\mathrm{Cs}$ and $\mathrm{K}$ breakthrough profiles in the standard simulant with $0.5 \mathrm{M} \mathrm{KNO}_{3}$, it should be noted that the $\mathrm{K}$ front moves through the column nearly instantaneousiy and reaches equilibrium as shown in Figure C.2. Thus, $C$ s enters a column, which is at equilibrium with $K$. Figure $C .2$ shows no rollug of $\mathrm{Cs}$, which would indicate the displacement of $\mathrm{Cs}$ for $\mathrm{K}$. Thus, although the presence of $\mathrm{K}$. reduces the amount of $\mathrm{Cs}$ loaded on the solid, $\mathrm{K}$ does not displace $\mathrm{Cs}$ from the solid.

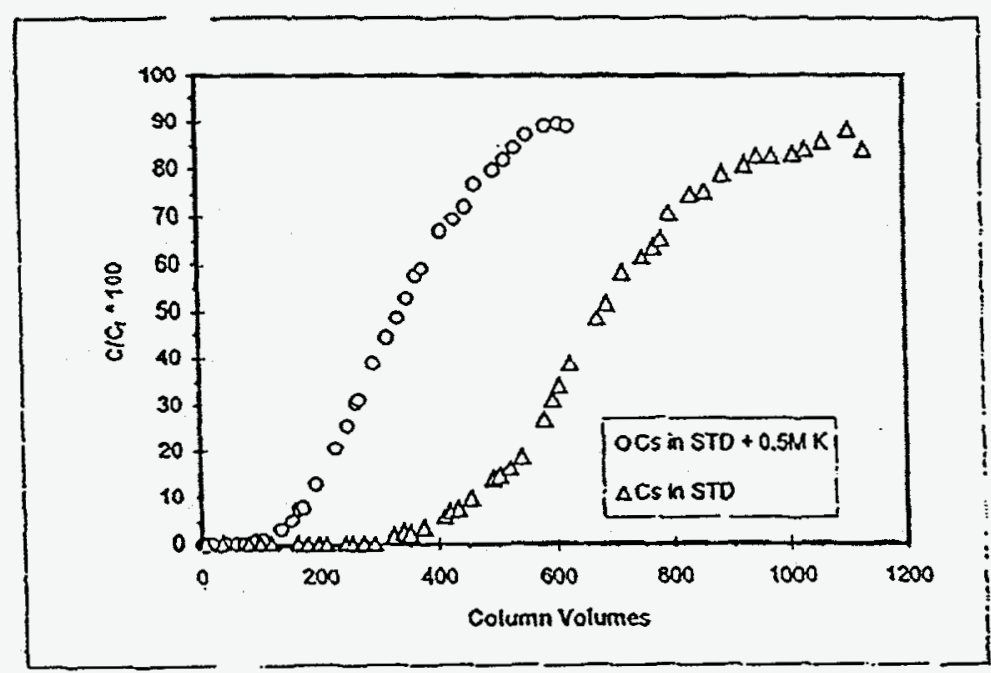

Figure C.1. Cs breakthrough profiles in standard (STD) and standard $+0.5 \mathrm{MK}$ simulants for the UOP IE-911-94 granules (400 micron diameter). Feed concentration was 50 ppm Cs. For the standard simulant run (IML8) the flow rate was $3.6 \mathrm{CV} / \mathrm{h}(3.9 \mathrm{~cm} / \mathrm{min})$. For the experiment (IML9) in standard with $0.5 \mathrm{M} \mathrm{K}$ the flow rate was $3.4 \mathrm{CV} / \mathrm{h}(3.6 \mathrm{~cm} / \mathrm{min})$. Both experiments were conducted in a $1.1 \mathrm{~cm}$ diameter and $31.75 \mathrm{~cm}$ long column (bcd volume $=30 \mathrm{~cm}^{3}$ ). 
APPENDIX B (continued)

Figure C.2. Cs and $\mathrm{K}$ breakthrough profiles for UOP IE-911-94 granules (400 micron diamcter) in standard simulant with $0.5 \mathrm{MKNO}_{3}$ and $50 \mathrm{ppm} \mathrm{Cs}$. The experiment number is IML11. The flow rate was $3.8 \mathrm{CV} / \mathrm{h}(4.2 \mathrm{~cm} / \mathrm{min})$ and bed porosity was 0.5 . The column dimensions were $1.1 \mathrm{~cm}$ diameter by $31.75 \mathrm{~cm}$ length for a total bed volume of $30 \mathrm{~cm}^{3}$.

(6) Texas A\&M University-Department of Chemical Engineering. 


\section{An Example of A Worst Case Design Composition}

To illustrate how important it is to understand the range of possible column feed compositions and their effect on the ion exchange carousel design, it is instructive to look at the waste labeled MVST-29. The information below adds two waste compositions to those already considered in the main body of this report. The first new composition is that of MVST-29 as provided by Roy Jacobs and is labeled MVST. The second new waste follows the same isotherm as MVST-29, but has a $\mathrm{Cs}^{+}$concentration of 19ppm and is labeled MVST-29-b.

As menlioned in the text of the report, we have identified three aspects of the isotherm which soem to affect the design. These factors are 1) the distribution coefficient, 2) the $\mathrm{Cs}^{+}$ concentration, and 3) the shape of the isotherm or the non-linearity of the isotherm. The table below quantifies the first two factors and qualifies the last for four representative wastes plus the two new wastes.

\begin{tabular}{cccc}
\hline Waste & Kd & $\mathrm{Cs}^{+}$conc. & Non-linearity \\
\hline MVST-29 & 584 & $1.3 \mathrm{ppm}$ & Medium \\
MVST-29-b & 485 & $19 \mathrm{ppm}$ & Very little \\
IXINO & 952 & $19 \mathrm{ppm}$ & Medium \\
HiNO-b & 353 & $93 \mathrm{ppm}$ & High \\
HiOH-b & 407 & $93 \mathrm{ppm}$ & High \\
Avg & 1060 & $19 \mathrm{ppm}$ & Medium
\end{tabular}

Table D.1. The waste composition factors which we have identified as playing a role in determining the ion exchange carousel design are quantified/qualified in this table. This table along with Figures 2.2, D.1, and D.2 illustrate that the distribution is a poor guide to identifying the conservative design cases.

Figures D. 1 and D.2 are the same as Figures 2.2 and 2.3 except that MVST and MVST- $b$ arc included. The figures show that MVST is a worst case composition requiring a space velocity much slower than any of the other six wastes. However, the increased $\mathrm{Cs}^{4}$ concentration for MVST-b causes it fall between HiNO and Avg. The graphs illustrate the importance of identifying the worst case compositions. Wastes compositions such as MVST can be managed in an upstream blending program so that the actual feed to the carosel falls within rcasonablc limits. 


\section{APPENDIX B (continued)}

D-2

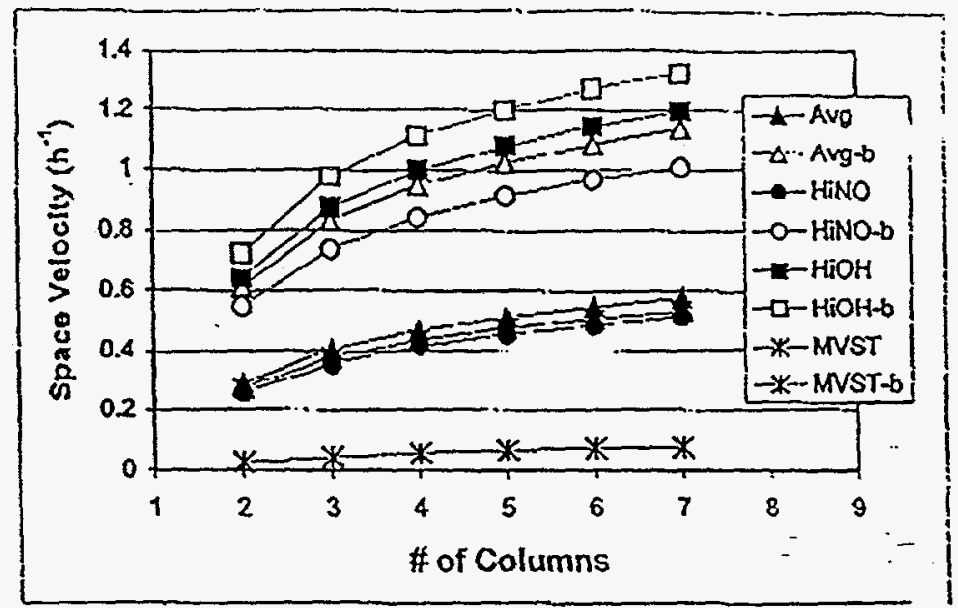

Figure D.1. Required space velocity (based on the total carouscl volume) versus the number of columons in the system for the original six waste compositions plus the two additional compositions. MVST is by far the worst case, but MVST-b falls between HiNO and Avg.

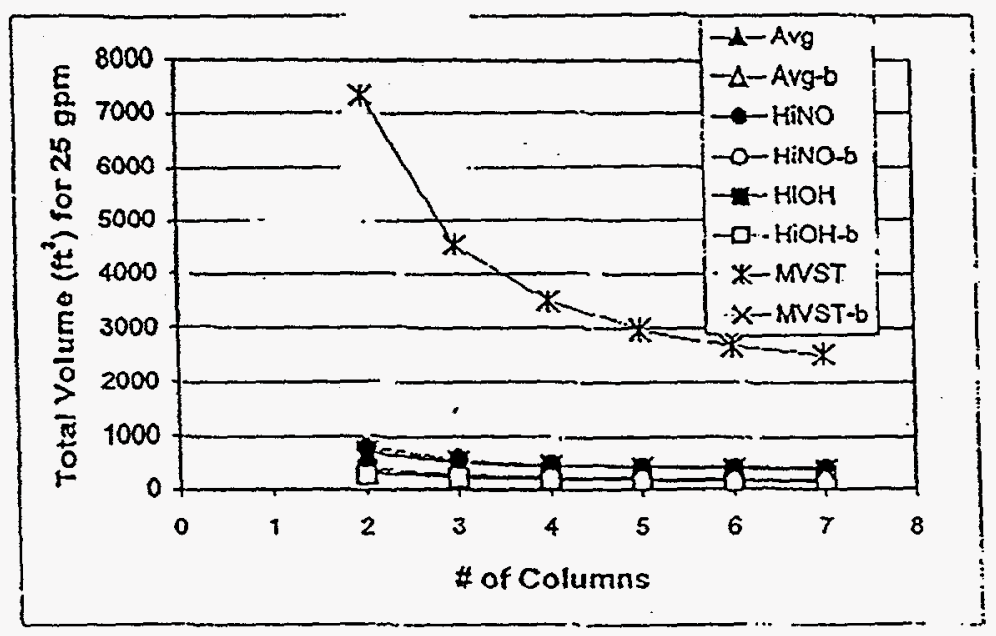

Figure D.2. Required total carousel volume (based on a $25 \mathrm{gpm}$ flow rate and calculated from Figure D.1) versus the number of columns in the system for six waste compositions. MVST is by far the worst case, but MVST-b falls between HiNO and Avg. 


\section{APPENDIX B (continued)}

\section{E. Ion Exchange Column Design Based on $80 \%$ Loading in the Lead Column.}

The Texas A\&M carousel model was used to consmuct design curves with space velocity as the design variable similar to those shown in Part 2 of this report. For these cases, the design criteria was modified to require an effluent concentration of $80 \%$ of the feed concentration from the lead column rather than the $90 \%$ requirement used for the design in Parts $l$ and 2. Figure B.1 plots the space velocity required to meet the column effluent specifications at steady state versus the number of columns in series for the six waste compositions. The space velocity is based on the total volume of ion exchange bed in the carousel. Figure E.2 contains the same information, but the space velocity is used to calculate a total required volume of the ion exchange bed based on a flow rate of $25 \mathrm{gpm}$. Figure E.3 shows the time interval between column switches.

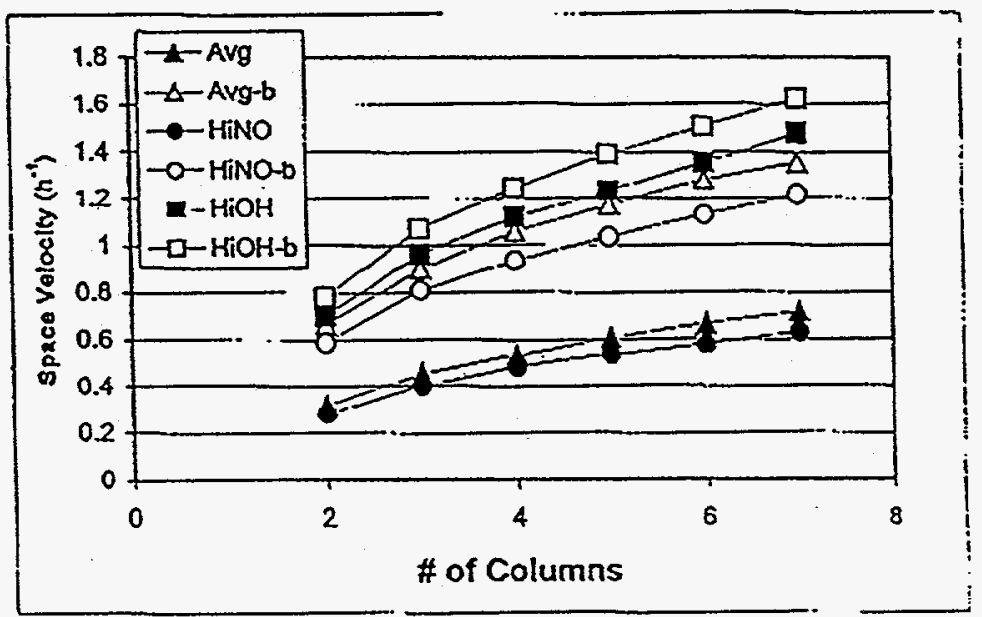

Figure E.1. Required space velocity (based on the total carousel volume) versus the number of columns in the system for six waste compositions. These curves are basod on a $\mathrm{Cs}^{+}$ concentration of $80 \%$ in the effluent from the first column when the last column reaches $1.3 \mathrm{ppb}$. 


\section{APPENDIX B (continued)}

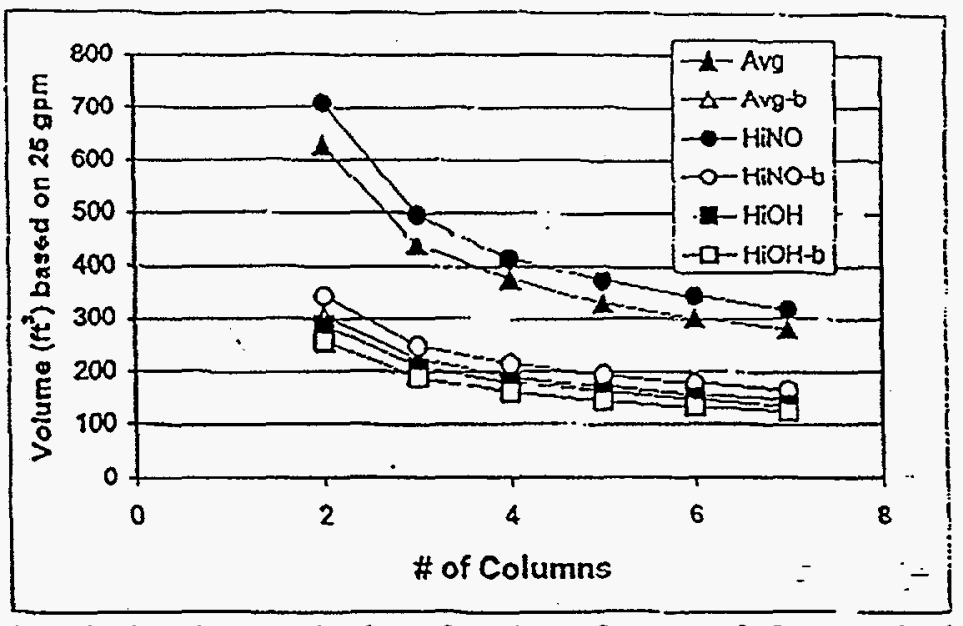

Figure E2. Required total carousel volome (based on a flow rate of $25 \mathrm{gpm}$ and calculated from Figure E. L) versus the number of columns in the system for six waste compositions. These curves are based on a Cs ${ }^{+}$concentration of $80 \%$ in the effluent from the first column when the last column reaches $1.3 \mathrm{ppb}$.

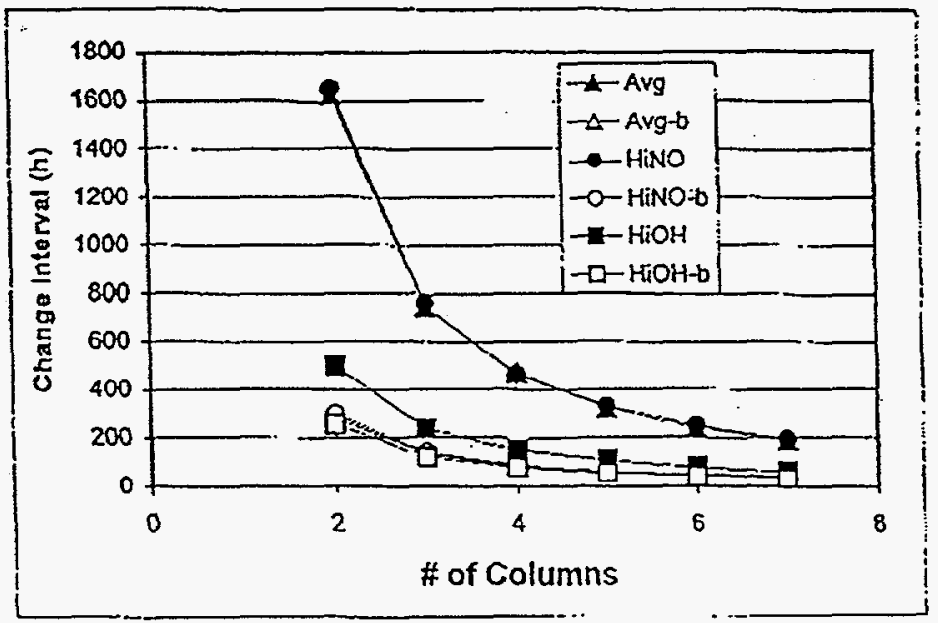

Figure E. 3. Interval between column switches versus the number of columns in the system for six waste compositions. The rate of CST usage is calculated by dividing the individual column volume by the switch interval. These curves are based on a $\mathrm{Cs}^{+}$concentration of $80 \%$ in the efflucnt from the first column when the last column reaches $1.3 \mathrm{ppb}$.

(9) Texas A\&M University- Deparunear of Chemical Engineering. 
APPENDIX B (continued)

\section{F . SRS Waste Compositions Studied for Base Design Cases}

The SRS waste compositions used in the ion exchange column design for the base cases presented in Part 1 of this report are shown here. The three waste compositions considered were labeled Avg, HiOH, and HiNO. For each waste, a nominal and bounding composition were provided resulting in six total waste compositions. Tables F.1 lists the nominal and bounding compositions of these wastes as was described by $R$. Jacobs.

Table F.1. SRS waste compositions in mol/L. The ' $\mathrm{n}$ ' represents 'hominal' composition and the 'b' indicates 'bounding' composition.

\begin{tabular}{|c|c|c|c|c|c|c|}
\hline Component & Avg-n & Arg-b & HiOH-n & HIOH-b & HiNO-n & HiNO-b \\
\hline $\mathrm{Na}^{+}$ & 5.6 & 5.47 & 5.6 & 5.48 & 5.6 & 5.45 \\
\hline $\mathrm{K}^{+}$ & 0.015 & 0.15 & 0.030 & 0.15 & 0.0041 & 0.15 \\
\hline $\mathrm{Cs}^{4}$ & 0.00014 & 0.0007 & 0.00037 & 0.0007 & 0.00014 & 0.0007 \\
\hline $\mathrm{AlO}_{2}^{-}$ & 0.31 & 0.31 & 0.27 & 0.27 & 0.32 & 0.32 \\
\hline $\mathrm{C}_{2} \mathrm{O}_{4}^{2-}$ & 0.008 & 0.008 & 0.008 & 0.008 & 0.008 & 0.008 \\
\hline $\mathrm{CO}_{3}^{2-}$ & 0.16 & 0.16 & 0.17 & 0.17 & 0.16 & 0.16 \\
\hline $\mathrm{MoO}_{4}^{2-}$ & 0.0002 & 0.0002 & 0.0002 & 0.0002 & 0.0002 & 0.0002 \\
\hline $\mathrm{SiO}_{3}^{2-}$ & 0.004 & 0.004 & 0.004 & 0.004 & 0.004 & 0.004 \\
\hline $\mathrm{SO}_{4}^{2-}$ & 0.15 & 0.15 & 0.030 & 0.030 & 0.22 & 0.22 \\
\hline $\mathrm{PO}_{4}^{3-}$ & 0.010 & 0.010 & 0.008 & 0.008 & 0.010 & 0.010 \\
\hline $\mathrm{Cl}^{-}$ & 0.025 & 0.025 & 0.010 & 0.010 & 0.040 & 0.040 \\
\hline $\mathrm{FO}^{-}$ & 0.032 & 0.032 & 0.010 & 0.010 & 0.050 & 0.050 \\
\hline $\mathrm{NO}_{2}^{-}$ & 0.52 & 0.52 & 0.74 & 0.74 & 0.37 & 0.37 \\
\hline $\mathrm{NO}_{3}^{-}$ & 2.14 & 2.14 & 1.10 & 1.10 & 2.84 & 2.84 \\
\hline $\mathrm{OH}^{-}$ & 1.91 & 1.91 & 3.05 & 3.05 & 1.17 & 1.17 \\
\hline
\end{tabular}


APPENDIX B (continued)

\section{G. Model Equations}

\section{Column Material Balance}

The differential material balance for component $i$ in a column containing a flowing fluid at constant density and operating in a region of dispersed flow is as follows:

$\frac{\partial C_{1}}{\partial t}=D \frac{\partial^{2} C_{1}}{\partial x^{2}}-v_{1} \frac{\partial C_{1}}{\partial x}-\frac{\left(I-\varepsilon_{w}\right)}{\varepsilon_{z}} \frac{\partial \psi}{\partial t}$

where

$\Psi_{i}=\frac{1}{V_{p}} \int_{0}^{V_{p}} \varepsilon_{p} \bar{C}, d V+\frac{1}{V_{p}} \int_{0}^{V_{p}}\left(1-\varepsilon_{p}\right) q_{i} d V \equiv$ average particle phase concentration.

Tho boundary conditions are required, one at the column inlet and one at the column outlct. Danckwerts boundary conditions are used and are written as

$\left.\frac{\partial C_{3}}{\partial x}\right|_{x=0}=\frac{V_{1}}{D}\left(C_{i}^{i}-\left.C_{1}\right|_{x \rightarrow 0}\right)$, and $\left.\frac{\partial C_{j}}{\partial x}\right|_{x=L}=0$.

The 2xial dispersion coefficient is calculatod from the correlation suggestod by Sucuki and Smith. This correlation has been validated by experimental dispersion studies on a laboratory column using IONSIV IE9L1 at Texas A\&M. An energy balance is not included because the ion exchange is considered isothermal.

\section{Particle Material Balance}

The particle is visualized as a two-phase porous particle containing a network of pores throughout a solid structure with diffusion occuning through the liquid filled pores. The resistance to diffusion of component $i$ is assumed the same in all pores. Fick's law is used as the constitutive oquation for diffusive flux. The differenlial material balance is written as

$$
\frac{\partial \overline{\mathrm{C}}_{1}}{\partial t}\left[\varepsilon_{0}+\left(1-\varepsilon_{\mathrm{p}}\right) \frac{\partial \mathrm{q}_{1}}{\partial \overline{\mathrm{C}}_{1}}\right]=-\frac{1}{\mathrm{r}^{2}} \frac{\partial}{\partial \mathrm{r}}\left[\mathrm{r}^{2} \mathrm{D}, \frac{\partial \overline{\mathrm{C}}_{1}}{\partial \mathrm{r}}\right]
$$

The particle material balance is coupled to the column material balance by Equation 9, which includes a film mass transfer coefficient that quanlifies the resistance to diffusion across a stagnant liquid film surrounding the particle. The mass transfer coefficient is estimated from Equation 16.71 in Perry's Handbook for Chemical Engineers.

(c) Texas A\&M University- Department of Chemical Engineering. 


\section{APPENDIX B (continued)}

$\frac{\partial \psi_{1}}{\partial t}=\left.\frac{3}{R_{p}} D_{e} \frac{\partial \bar{C}_{i}}{\partial r}\right|_{r=R_{i}}=\frac{3}{R_{p}} k_{f}\left(C_{i}-C_{i}^{s}\right)$.

In addition, local equilibrium between the solid phase and the liquid phase within the pores is assumod. Thus, at each point in the particle,

$q_{i}=F\left[\bar{C}_{i}\right] \equiv$ Solid $/$ liquid equilibrium isotherm.

\section{List of Symbols.}

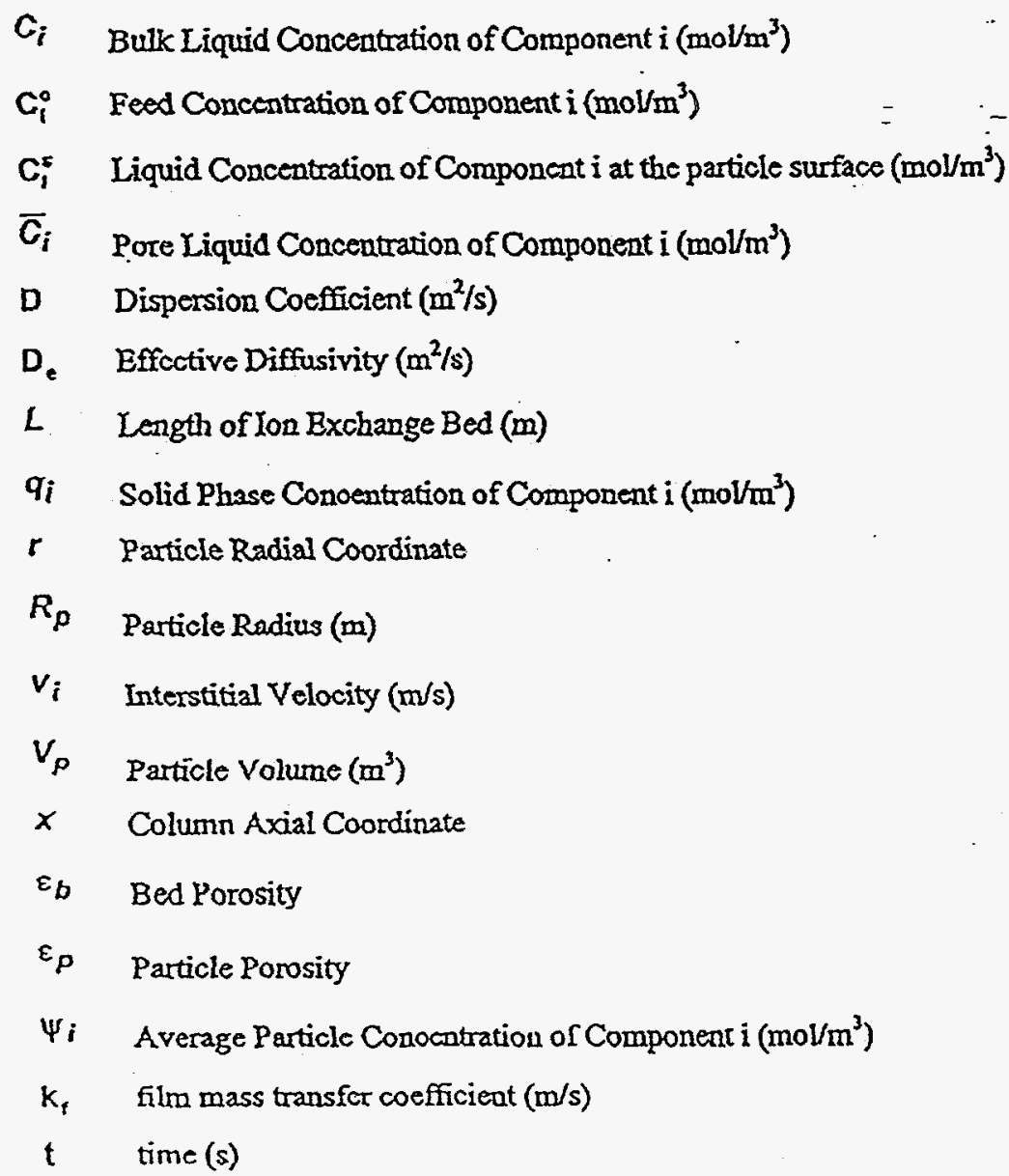


WSRC-TR-98-00343 Rev.0

Page 68 of 69

APPENDIX B (continued)

THIS PAGE INTENTIONALLY LEFT BLANK 
CC: G. E. Abell, 704-3N

B. N. Attaway, 773-A

J. L. Barnes, 704-3N

M. J. Barnes, 773-A

S. B. Beck, 704-3N

N. E. Bibler, 773-A

J. D. Carlson, 703-H

J. T. Carter, 704-25S

G. L. Cauthen, 241-119H

W. C. Clark, 704-56H

C. L. Crawford, 773-41A

Dr. E. Cussler, 704-3N

N. R. Davis, 703-H

R. A. Dimenna, 773-42A

L. O. Dworjanyn, 779-2A.

R. E. Eibling, 704-T

H. H. Elder, 704-S

S. D. Fink, 773-A

F. Fondeur, 773-62A

J. R. Fowler, 704-3N

M. W. Geeting, 773-24A

J. C. Griffin, 773-A

T. Hang, 773-42A

D. T. Hobbs, 773-A

E. W. Holtzscheiter, 773-A

P. I. Hudson, 704-3N

R. A. Jacobs, 704-3N

M. D. Johnson, 703-H

M. T. Keefer, 241-153H

P. S. Kirkland, 703-46A

E. J. Kosiancic, 704-3N

L. F. Landon, 704-T

B. L. Lewis, 703-H
T. J. Lex, 703-H

P. E. Lowe, 773-41A

D. J. McCabe, 773-42A

J. W. McCollough, 703-H

M. S. Miller, 704-56H

T. M. Monahon, 703-H

J. P. Morin, 703-H

E. T. Murphy, 704-3N

C. A. Nash, 773-42A

L. M. Nelson, 773-43A

L. M. Papouchado, 773-A

P. K. Paul, 773-42A

R. A. Peterson, 773-A

S. F. Piccolo, 704-3N

M. R. Poirier, 676-T

M. J. Polochko, 773-A

K. J. Rueter, 706-S

P. L. Rutland, $704-196 \mathrm{~N}$

R. H. Spires, 703-H

W. E. Stevens, 773-A

P. C. Suggs, $704-3 \mathrm{~N}$

R. F. Swingle, 773-A

W. L. Tamosaitis, 773-A

G. A. Taylor, $704-196 \mathrm{~N}$

W. B. VanPelt, 676-1T

D. D. Walker, 773-A

Dr. J. Watson, 704-3N

W. R. Wilmarth, 773-42A

G. T. Wright, 773-A

J. E. Young, 773-A

TIM, 703-43A

WPTS Files, 773-A, c/o S. Poston, 773-A

ITP files, c/o A. G. Wiest, 241-119H 